\title{
CORONAVIRUS
}

Cite as: Z. Wang et al., Sci. Transl. Med.

10.1126/scitranslmed.abf1555 (2020).

\section{Enhanced SARS-CoV-2 neutralization by dimeric IgA}

\author{
Zijun Wang $^{1 \dagger}$, Julio C. C. Lorenzi $^{1 \dagger}$, Frauke Muecksch ${ }^{2 \dagger}$, Shlomo Finkin ${ }^{1+}$, Charlotte Viant ${ }^{1}$, Christian Gaebler ${ }^{1}$, \\ Melissa Cipolla ${ }^{1}$, Hans-Heinrich Hoffmann ${ }^{3}$, Thiago Y. Oliveira', Deena A. Oren ${ }^{4}$, Victor Ramos', Lilian \\ Nogueira' ${ }^{1}$ Eleftherios Michailidis ${ }^{3}$, Davide F. Robbiani ${ }^{5}$, Anna Gazumyan', Charles M. Rice ${ }^{3}$, Theodora \\ Hatziioannou $^{2}$, Paul D. Bieniasz ${ }^{2,6}$, Marina Caskey ${ }^{1}$, Michel C. Nussenzweig ${ }^{1,6^{*}}$
}

\begin{abstract}
${ }^{1}$ Laboratory of Molecular Immunology, The Rockefeller University, New York, NY, 10065, USA. ²aboratory of Retrovirology, The Rockefeller University, New York, NY, 10065, USA. ${ }^{3}$ Laboratory of Virology and Infectious Disease, The Rockefeller University, New York, NY, 10065, USA. ${ }^{4}$ Structural Biology Resource Center, The Rockefeller University, New York, NY 10065, USA 5 Institute for Research in Biomedicine, Università della Svizzera italiana, 6500, Bellinzona, Switzerland. ${ }^{\circ H}$ oward Hughes Medical Institute, The Rockefeller University, New York, NY, 10065 USA.
\end{abstract}

†Equal contributions

*Corresponding author. Email: nussen@rockefeller.edu (M.C.N)

Severe acute respiratory syndrome coronavirus 2 (SARS-CoV-2), the virus that causes coronavirus disease 2019 (COVID-19), primarily infects cells at mucosal surfaces. Serum neutralizing antibody responses are variable and generally low in individuals that suffer mild forms of COVID-19. Although potent IgG antibodies can neutralize the virus, less is known about secretory antibodies such as IgA that might impact the initial viral spread and transmissibility from the mucosa. Here we characterize the IgA response to SARS-CoV-2 in a cohort of 149 convalescent individuals following diagnosis with COVID-19. IgA responses in plasma generally correlated with IgG responses. Further, clones of IgM-, IgG-, and IgA-producing B cells were derived from common progenitor cells. Plasma IgA monomers specific to SARS-CoV-2 proteins were demonstrated to be two-fold less potent than IgG equivalents. However, IgA dimers, the primary form of antibody in the nasopharynx, were on average fifteen times more potent than IgA monomers against the same target. Thus, dimeric IgA responses may be particularly valuable for protection against SARS-CoV-2 and for vaccine efficacy.

\section{INTRODUCTION}

Severe acute respiratory syndrome coronavirus 2 (SARS$\mathrm{CoV}-2$ ) encodes a trimeric spike surface protein (S) which mediates entry into host cells $(1,2)$. The virus initially infects epithelial cells in the nasopharynx when the receptor binding domain (RBD) of $\mathrm{S}$ interacts with the angiotensin converting enzyme-2 (ACE-2) receptor (3-6). SARS-CoV-2 may subsequently spread to other epithelial cells expressing ACE-2 in the lung and gut. These tissues are rich in lymphoid cells that are organized into nasopharynx-associated and gut-associated lymphoid tissues (NALT and GALT respectively). Vaccines delivered by inhalation to specifically target these tissues appear to be more effective in providing sterilizing protection against SARS-CoV-2 (7). Among other specializations, NALT and GALT produce large quantities of IgA antibodies. These antibodies exist as monomers in circulation where they make up $15 \%$ of the serum antibody pool in healthy individuals. However, IgA is found in higher concentrations in secretions from mucosal surfaces, where it exists predominantly as a dimer covalently linked by $\mathrm{J}$ chain (8-10).

Although most individuals produce antibodies in response to SARS-CoV-2 infection, the neutralizing antibody response is highly variable, with as many as $30 \%$ of the population producing antibodies with neutralizing activity below 1:50 in pseudovirus neutralization assays $(11,12)$. Higher neutralization titers and plasma RBD binding activity are associated with prolonged infection, which is likely due to prolonged exposure to the virus (11-13). IgG antibody cloning experiments from recovered individuals have revealed that neutralizing antibodies target several distinct and non-overlapping epitopes on the RBD (11, 14-18). Some of these antibodies are potently neutralizing and can prevent or treat infection in animal models (15-19). Moreover, longitudinal studies indicate that these antibodies may also be protective in humans (20-22). In a cohort of 113 individuals of varying disease severity, anti-RBD antibody levels and neutralizing activity were predictive of disease outcome (20). Individuals that developed higher neutralizing titers earlier ultimately fared better (20), as did hospitalized individuals that developed higher anti-spike antibody titers (21).

Consistent with the fact that SARS-CoV-2 initially infects in the nasopharynx, IgA antibodies that bind to SARS-CoV-2 are produced rapidly after infection and remain elevated in the plasma for at least 40 days after the onset of symptoms 
(23-26). While some viruses, such as influenza virus, show increased susceptibility to dimeric forms of antibodies such as IgA (27-29), others with lower spike densities that cannot be crosslinked by antibodies, like human immunodeficiency virus (HIV)-1, do not (30). IgA antibodies have been shown to bind to the RBD of SARS-CoV-2 and can neutralize the virus (23-25). However, the precise contribution and molecular nature of the IgA response to SARS-CoV-2 has not been reported to date.

Here we examined a cohort of 149 convalescent individuals who had confirmed infection with SARS-CoV-2 and their close contacts who had measurable plasma neutralizing activity to investigate the contribution of IgA to anti-SARS-CoV2 antibody response. The individuals were part of a cohort of SARS-CoV-2 infected people that represent a spectrum of illness severity from mild to hospitalized, all of which survived the infection (11). Cloning IgA antibodies from single B cells revealed that the neutralizing activity of monomeric IgA is generally lower than corresponding IgG monomers but dimeric IgA antibodies are on average 15 -fold more potent than their monomeric counterparts.

\section{RESULTS}

\section{Plasma anti-SARS-CoV-2 RBD IgA}

IgM, IgG and IgA account for $5 \%, 80 \%$ and $15 \%$ of the antibodies in plasma, respectively. IgG responses to RBD are strongly correlated with neutralizing activity (11, 13-17, 3135). To examine the contribution of IgA to the anti-SARSCoV-2 RBD response, we tested plasma samples for binding to the RBD by a validated ELISA. A positive control sample (COV-21) was included for normalization of the area under the curve (AUC) and eight independent healthy donor samples were included as negative controls (Fig. 1A). We identified some binding of RBD by IgA and IgM antibodies from healthy donors, similar to that reported for IgG. This binding may reflect some cross-reactivity with seasonal coronaviruses (11). Whereas $78 \%$ and $15 \%$ of the individuals in this cohort showed IgG and IgM anti-RBD concentrations that were at least two standard deviations above control, only $33 \%$ did so for IgA (Fig. 1A and B, (11)). Thus, in individuals studied on average 40 days after infection the circulating concentrations of anti-RBD IgA are more modest than IgG and higher than IgM.

Anti-RBD IgA titers were correlated with duration $(P=$ $0.005)$ and severity of symptoms $(P<0.0001)$ but not timing of sample collection relative to onset $(P=0.69)$ or age $(P=$ $0.22)$, Fig. 1C-F). Concentrations of anti-RBD IgA antibodies correlated strongly with anti-RBD IgG concentrations $(P<$ 0.0001), Fig. 1G). Similar to IgG, females had lower concentrations of RBD-specific IgA than males $(P=0.002$, Fig. $1 \mathrm{H})$ and hospitalized individuals showed higher anti-RBD IgA titers than those with milder symptoms $(P=0.004$, Fig. 1I). In addition, cases had higher anti-RBD IgA titers than contacts $(P=0.025$, Fig. 1J). Of note, individuals that suffered gastrointestinal symptoms showed significantly higher plasma antiRBD IgA $(P=0.003$, Fig. $1 \mathrm{~K})$ but not IgG titers $(P=0.06$, Fig. 1L).

\section{Neutralization activity of purified IgG and IgA}

To compare the neutralizing activity of plasma IgA to IgG directly we purified both isotypes from the plasma of all 99 individuals in our cohort that showed measurable plasma neutralizing activity and tested the two isotypes in an HIV-1based SARS-CoV-2 pseudovirus neutralization assay $(11,34)$. Plasma IgG $(P<0.0001$, Fig. $2 \mathrm{~A})$ and $\operatorname{IgA}(P=0.0005$, Fig. 2B $)$ binding to RBD was directly correlated to their neutralizing activity and to the neutralizing activity in plasma (Fig. $2 \mathrm{C}$ and $2 \mathrm{D}, P<0.0001$ respectively). In addition, there was good correlation between the neutralizing activity of IgG and IgA in a given individual $(P<0.0001$, Fig. $2 \mathrm{E})$. However, potency of each of the two isotypes varied by as much as two orders of magnitude between individuals $(P<0.0001$, Fig. $2 F)$. Purified IgG was generally more potent than IgA in neutralizing SARS-CoV-2 pseudovirus in vitro. The geometric mean halfmaximal inhibitory concentrations $\left(\mathrm{IC}_{50}\right)$ for $\mathrm{IgG}$ was $384 \mathrm{nM}$ vs. $709 \mathrm{nM}$ for IgA (Fig. 2F). Nevertheless, IgA antibodies were more potent than IgG antibodies in $25 \%$ of the individuals tested (Fig. 2G). The two isotypes also differed in that the overall potency of purified IgG was correlated with symptom severity $(P=0.0002$, Fig. $3 \mathrm{~A})$, but purified IgA was not $(P=0.15$, Fig. $3 \mathrm{~B})$. Likewise, potency of purified IgG was correlated with timing of sample collection relative to onset, but purified IgA was not $(P=0.020$ and $P=0.15$, Fig. $3 \mathrm{C}$ and $\mathrm{D})$. Neutralizing activities of purified IgG and IgA were not correlated with age, duration of symptoms, or sex (fig. S1). The potency of purified IgG was higher in hospitalized individuals $(P=0.009$, Fig. $3 \mathrm{E})$, but for IgA this was not the case $(P=$ 0.98 , Fig. 3F). Finally, the potency of the purified IgA $(P=$ $0.036)$, but not IgG $(P=0.09)$, was greater in individuals that suffered from gastrointestinal symptoms (Fig. 3G and H).

\section{Monoclonal anti-SARS-CoV-2 IgM and IgA antibodies}

To characterize the IgM and IgA anti-RBD antibodies elicited by SARS-CoV-2 infection we used flow cytometry to purify single B lymphocytes that bind to RBD and cloned their antibodies. We obtained 109 IgM and 74 IgA (64 IgA1 and 10 IgA2) matched Ig heavy and light chain sequences by reverse transcription and subsequent isotype specific PCR from three convalescent individuals (Fig. 4A, B). As reported for IgG antibodies $(11,14,17,33,36)$, the overall number of mutations was generally low when compared to antibodies obtained from individuals suffering from chronic infections such as Hepatitis-B or HIV-1 $(37,38)$ (fig. S2). However, the number of $\mathrm{V}$ gene nucleotide mutations in IgM and IgA heavy and light chains varied between individuals. For example, in donor COV21 the number of IgM and IgA heavy chain mutations 
was similar. In contrast, IgM heavy and light chain nucleotide mutations were significantly greater than IgA mutations in COV47 $(P<0.0001$, fig. S2B). The relatively unexpected similarity between the number of somatic mutation in IgM and IgG could be due to the timing of sample collection early in the immune response before full maturation of the germinal center wherein most IgG producing memory cells acquire their mutations (39).

Complementarity-determining region 3 (CDR3) length was significantly shorter for IgM than IgA and IgG antibodies $(P<0.001$, fig. S3) and hydrophobicity was higher for IgM over control but not for IgA and IgG (fig. S4). Compared to the normal human antibody repertoire, several IgA and IgM VH genes were over-represented, including VH3-53, which can make key contacts with the RBD through germline encoded CDRH1 and CDRH2 (11, 40, 41) (fig. S5).

Like IgG antibodies (11) IgA and IgM antibodies were found in expanded clones in all three of the individuals examined. Overall $66.2 \%$ and $66.1 \%$ of all the IgA and IgM sequences examined were members of expanded clones (Fig. 4A, B and data file S1). Nearly identical sequences were shared among the three isotypes in clones found in all three individuals, indicating that switch recombination occurred during B cell clonal expansion in response to SARS-CoV-2 (Fig. 4B and C). In total 11 out of 55 antigen-specific B cell clones in circulation belonged to expanded clones that contained members expressing different constant regions (Fig. 4C and data file S1 and data file S2). When compared directly, the neutralizing activity of antibodies that were members of B cell clones producing IgA or IgG varied and did not correlate with one or the other isotype (table $\mathrm{S} 1$ ).

To examine the binding properties of the anti-SARS-CoV2 monoclonal antibodies we expressed 46 IgM and 35 IgA antibodies by transient transfection (data file S3). IgM variable regions were produced on an IgG1 backbone to facilitate expression and purification. IgA antibodies were expressed as native IgA1 or IgA2 monomers. ELISA assays on RBD showed that $100 \%$ and $91.3 \%$ of the IgA and IgM antibodies bound to the RBD with an average half-maximal effective concentration of $52.8 \mathrm{ng} / \mathrm{ml}$ and $101.6 \mathrm{ng} / \mathrm{ml}$ respectively (fig. S6A, B and data file $\mathrm{S} 4$ ).

To determine neutralizing activity of the IgM and IgA antibodies, we tested them against a human immunodeficiency virus 1-based SARS-CoV-2 pseudovirus as either IgG monomers or native IgA monomers, respectively. IgM antibodies were tested as IgG antibodies because of the difficulty in producing IgM pentamers. Among the 42 RBD binding IgM antibodies tested, we found 10 that neutralized the virus in the $\mathrm{ng} / \mathrm{ml}$ range with geometric mean half-maximal inhibitory concentrations $\left(\mathrm{IC}_{50}\right)$ of 114.0 nanograms per milliliter (Fig. $5 \mathrm{~A}$ and fig. S6C, data file S4). In contrast, 32 out of $35 \mathrm{RBD}$ binding IgA antibodies tested neutralized the virus in the $\mathrm{ng} / \mathrm{ml}$ range with geometric mean half-maximal inhibitory concentrations $\left(\mathrm{IC}_{50}\right)$ of 53.6 nanograms per milliliter (Fig. 5A and fig. S6C, data file S4). Thus, IgM antibodies expressed as monomeric IgG antibodies show lower neutralizing activity than either native IgA or IgG monomers (Fig. 5A).

To examine the epitopes targeted by the IgA antibodies with high neutralizing activity we performed biolayer interferometry experiments in which a preformed antibody-RBD complex consisting of anti-RBD antibodies representing Class 1, 2, 3 or 4 as determined by structural analysis (C144-, C121-, C135- or CR3022-RBD) were exposed to an IgA monoclonal (Fig. 5B and C) $(11,40,42)$. The IgA monoclonal antibodies bound to RBD with variable affinities (Fig. 5B). Seven of the IgA antibodies were in class 1 or 2 and competed with $\mathrm{C} 144$ or 121, and two others competed with $\mathrm{C} 135$ and were therefore in class 3 (Fig. 5C and fig. S7).

\section{Dimeric anti-SARS-CoV-2 IgA is more potent than mon- omeric IgA}

Mucosal IgA exists predominantly as a dimer of two IgA monomers covalently linked together by $\mathrm{J}$ chain. To compare the binding properties of IgA monomers and dimers, we coexpressed eight IgA1s and one IgA2 with $\mathrm{J}$ chain to produce mixtures of monomers and dimers that were purified by size exclusion chromatography (fig. S8). When tested in biolayer interferometry experiments, the dimers uniformly showed increased apparent affinities compared to the monomers by an average of 43.27 -fold ( $P=0.016$, Fig. $6 \mathrm{~A}$ and $\mathrm{B}$ ). To determine whether increased apparent affinity correlates with neutralizing activity, we compared the monomers and dimers in pseudovirus neutralization assays. All but one of the IgA dimers were more potent at neutralizing pseudovirus than the corresponding monomers with differences in activity ranging from 3.8 to 113 -fold (Fig. 6C, fig. S9A and table S2). The relative increase in neutralizing activity between monomer and dimer was inversely correlated with the neutralizing activity of the monomer in this assay (fig. S9B. $\mathrm{IC}_{50}: r=0.80, P=$ 0.014). For example, whereas C437, the most potent antibody, showed equivalent activity as a monomer and dimer, C408, one of the least potent antibodies, was 113-fold more potent as a dimer (fig. S9B).

IgA monomers and dimers were also compared in authentic SARS-CoV-2 microneutralization assays (Fig. 6D, fig. S9C and D). Neutralizing activities of the nine monomers and nine dimers correlated strongly with those measured in the pseudovirus neutralization assay ( $\mathrm{IC}_{50}: r=0.84, P<0.0001$; $\mathrm{IC}_{90}: r=0.91, P<0.0001$ fig. S9E). On average, there was a 15fold geometric mean increase in activity for the dimer over the monomer against SARS-CoV-2 and less variability in the degree of enhancement in microneutralization compared to pseudovirus assays (Fig. 6E and table S2). Thus, dimeric IgA is more potent than monomeric IgA against SARS-CoV-2 (Fig. $6 \mathrm{E})$. 


\section{DISCUSSION}

Neutralizing antibody titers are the best correlates of protection in most vaccines (43). Among antibody isotypes, secretory IgA, which is found at mucosal surfaces, plays a crucial role in protecting against pathogens that target these surfaces (44). Serum IgA monomers are produced by the same cells that produce secretory dimers and we find that serum IgA responses to SARS-CoV-2 correlate with IgG responses. Although the monomeric form of IgA found in serum is on average two-fold less potent than IgG, the dimeric, secretory form of IgA found in mucosa is over one log more potent than their respective monomer forms against authentic SARS-CoV-2, suggesting that dimeric IgA is a more potent neutralizer than IgG. The difference in neutralizing activity between the isotypes in serum could be due to differences in the developmental kinetics of the two isotypes during the immune response to this pathogen.

The increased potency of the dimeric form of IgA suggests that crosslinking the $\mathrm{S}$ protein on the viral surface enhances neutralizing activity either directly or simply through increased apparent affinity. This observation is consistent with the finding that monovalent Fab fragments of serum IgG antibodies are far less potent than the intact antibody (40). In addition, our findings are in agreement with previous reports demonstrating that influenza virus is more susceptible to neutralization by IgA dimers than monomers (27-29). Whether the effect we observed in the context of SARS-CoV2 is due to inter- or intra-spike crosslinking is not known, but it indicates that antibodies or drugs designed to block entry by binding to the RBD could be made more potent by increasing their valency.

Limitations of our study include not having tested the native secretory form of IgA in saliva or feces. In addition, we are unable to explain why the monomeric forms of IgG are more potent in neutralizing SARS-CoV-2 than monomeric IgA. We speculate that this might be due to differences in the precise mechanisms of selection for entry into the IgG or IgA memory or plasma cell compartments (45). Future studies will be necessary to mechanistically evaluate these differences.

A number of different candidate vaccines to SARS-CoV-2 are currently being evaluated in the clinic, including mucosally delivered vaccines that typically produce more robust mucosal immune responses (46). Secretory IgA responses may be particularly important to these efforts in that potent dimeric forms of these antibodies are found at the mucosal surfaces where cells are initially targeted by SARS-CoV-2. Thus, even vaccines that elicit modest neutralizing activity in serum may be protective because the secretory polymeric forms of antibodies in mucosa can neutralize the virus. Further, vaccines delivered via the mucosal route can elicit superior IgA responses (47-49). Whether vaccines that are specifically designed to elicit mucosal IgA responses will be particularly effective preventing SARS-CoV-2 infection remains to be determined (46).

\section{MATERIALS AND METHODS}

\section{Study design}

This goal of this study was to investigate the IgA response to SARS-CoV-2 in a cohort of 149 convalescent patients after diagnosis of COVID-19. First, we evaluated the overall binding and neutralizing activity of the plasma anti-RBD IgA, IgG and IgM antibodies; Secondly, we sequenced and analyzed the BCRs of single B cells from peripheral blood and characterized the three isotypes produced by $\mathrm{B}$ cells derived from three individual donors. Third, we cloned and expressed monoclonal IgA and IgM antibodies and tested their binding and neutralizing activities. Finally, we compared the affinity and neutralization potency of IgA monomers and dimers against SARS-CoV-2 pseudovirus and authentic SARS-CoV-2. Each experiment contained a minimum of two technical replicates.

Samples were obtained from 149 individuals under a study protocol approved by the Rockefeller University in New York from April 1 through May 8, 2020 as described in (11). All participants provided written informed consent before participation in the study and the study was conducted in accordance with Good Clinical Practice and clinical data collection. The study was performed in compliance with all relevant ethical regulations and the protocol was approved by the Institutional Review Board (IRB) of the Rockefeller University.

\section{Purification and quantification of IgA and IgG from plasma}

IgA and IgG were purified from samples with measurable neutralizing activity against SARS-CoV-2-RBD (11). 300 $\mathrm{\mu l}$ of plasma was diluted with phosphate buffered saline (PBS), heat-inactivated $\left(56^{\circ} \mathrm{C}\right.$ for 1 hour $)$ and incubated with peptide M/Agarose (Invivogen gel-pdm-5) or Protein G/Agarose (GE Life Sciences 17-0618-05) overnight at $4^{\circ} \mathrm{C}$. The suspension was transferred to chromatography columns and washed with 10 column volumes of $1 \mathrm{X}$-PBS. IgA and IgG were then eluted with $1.5 \mathrm{ml}$ of $0.1 \mathrm{M}$ glycine $(\mathrm{pH}=3.0)$ and $\mathrm{pH}$ was immediately adjusted to 7.5 with $1 \mathrm{M}$ Tris $(\mathrm{pH}=8.0)$. 1X-PBS buffer exchange was achieved using Amicon ${ }^{\circledR}$ Ultra centrifugal filters (Merck Millipore) through a $30-\mathrm{kD}$ membrane according to the manufacturer's instructions. IgA and IgG concentrations were determined by measurement of absorbance at $280 \mathrm{~nm}$ using a NanoDrop (Thermo Scientific) instrument and samples were stored at $4{ }^{\circ} \mathrm{C}$.

\section{ELISAs}

ELISAs to evaluate the IgG or IgA binding to SARS-CoV-2 RBD were performed as previously described using a 
validated assay $(50,51)$. High binding 96 half well plates (Corning \#3690) were coated with $50 \mu \mathrm{L}$ per well of a $1 \mu \mathrm{g} / \mathrm{mL}$ protein solution in PBS overnight at $4{ }^{\circ} \mathrm{C}$. Plates were washed 6 times with washing buffer containing 1xPBS with $0.05 \%$ Tween-20 (Sigma-Aldrich) and incubated with $170 \mu \mathrm{L}$ blocking buffer per well containing 1xPBS with $2 \%$ bovine serum albumin (BSA) and $0.05 \%$ Tween-20 (Sigma-Aldrich) for 1 hour at room temperature. Immediately after blocking, monoclonal antibodies or plasma samples were added in PBS and incubated for 1 hour at room temperature. Plasma samples were assayed at a 1:200 starting dilution and seven additional 3 -fold serial dilutions. Monoclonal antibodies were tested at $10 \mu \mathrm{g} / \mathrm{ml}$ starting concentration and ten additional 4-fold serial dilutions. Plates were washed 6 times with washing buffer and then incubated with anti-human IgG (Jackson Immuno Research 109-036-088) or anti-human IgA (Sigma-Aldrich A0295) secondary antibody conjugated to horseradish peroxidase (HRP) in blocking buffer at 1:5000 or 1:3000 dilution respectively. Plates were developed by addition of the HRP substrate, 3,3', 5,5"-tetramethylbenzidine (TMB, Thermo Fisher Scientific 34021) for $10 \mathrm{~min}$ (plasma samples) or $4 \mathrm{~min}$ (monoclonal antibodies), then the developing reaction was stopped by adding $50 \mu \mathrm{l} 1 \mathrm{M} \mathrm{H}_{2} \mathrm{SO}_{4}$. Optical density units (ODs) were measured at $450 \mathrm{~nm}$ in a microplate reader (FluoStar Omega, BMG Labtech). For plasma samples, a positive control (plasma from patient COV21, diluted 200-fold in PBS) and negative control historical plasma samples was added in duplicate to every assay plate for validation. The average of its signal was used for normalization of all the other values on the same plate with Excel software.

\section{Cell lines}

HT1080 $_{\text {Ace2 }}$ cl.14 cells (34), $293 \mathrm{~T}_{\text {Ace2 }}$ cells (11) and Vero E6 kidney epithelial cells were cultured in Dulbecco's modified Eagle medium (DMEM) supplemented with $10 \%$ fetal calf serum (FCS) at $37^{\circ} \mathrm{C}$ and $5 \% \mathrm{CO}_{2}$. In addition, medium for Ace2overexpressing cell lines contained $5 \mu \mathrm{g} / \mathrm{ml}$ blasticidin and medium for Vero E6 cells was supplemented with 1\% nonessential amino acids. All cell lines have tested negative for contamination with mycoplasma and parental cell lines were obtained from the American Type Culture Collection (ATCC).

\section{Pseudotyped virus neutralization assay}

SARS-CoV-2 pseudotyped particles were produced by cotransfection of pSARS-CoV-2 $\mathrm{S}_{\text {trunc }}$ and pNL4-3 $\triangle$ Env-nanoluc in 293T cells $(11,34)$. Four-fold serially diluted purified plasma IgG/IgA from COVID-19 convalescent individuals and healthy donors or monoclonal antibodies were incubated with the SARS-CoV-2 pseudotyped virus for 1 hour at $37^{\circ} \mathrm{C}$ degrees. Subsequently, the mixture was incubated with Ace2expressing cells for 48 hours. $\mathrm{HT}_{1080_{\mathrm{Ace} 2}}$ cl. 14 cells (34) were used for plasma-derived IgG or IgA assays and $293 \mathrm{~T}_{\mathrm{Ace} 2}$ cells (11) for monoclonal antibody assays. Following incubation, cells were washed twice with PBS and lysed with Luciferase Cell Culture Lysis 5x reagent (Promega, E1531). Nanoluc Luciferase activity in lysates was measured using the Nano-Glo Luciferase Assay System (Promega, N1150) with a GloMax Navigator Microplate Luminometer (Promega). Relative luminescence units obtained were normalized to those derived from cells infected with SARS-CoV-2 pseudotyped virus in the absence of plasma-derived or monoclonal antibodies. The half-maximal and 90\% inhibitory concentrations for purified plasma IgG or IgA or monoclonal antibodies ( $\mathrm{IC}_{50}$ and $\mathrm{IC}_{90}$ ) were determined using 4-parameter nonlinear regression (GraphPad Prism).

\section{Antibody sequencing, cloning and expression}

Single B cells were isolated from COV21, COV47 and COV96 patients as previously described (11). Briefly, RNA from single cells was reverse-transcribed (SuperScript III Reverse Transcriptase, Invitrogen, 18080-044) using random primers (Invitrogen, 48190011) and followed by nested PCR amplifications and sequencing using the primers for heavy chain that are listed in data file S5 and primers for light chains from (52). Sequence analysis was performed with MacVector. Antibody cloning from PCR products was performed by sequencing and ligation-independent cloning into antibody expression vectors (Ig $\curlyvee 1-, I_{K}-, \operatorname{IG} \lambda-, \operatorname{Ig} \alpha 1$ and $\left.\operatorname{Ig} \alpha 2\right)$ as detailed in (53). The Ig $\alpha 1$ and $\operatorname{Ig} \alpha 2$ vectors were from (Invivogen, pfusess-hchalfor IgA1 and pfusess-hcha2m1 for IgA2). J chain plasmid was a gift from Susan Zolla-Pazner. Recombinant monoclonal antibodies were produced and purified as previously described $(52,54)$. Briefly, monoclonal antibodies were produced by transient co-transfection of 293-F cells with human heavy chain and light chain antibody expression plasmids using polyethylenimine (Sigma-Aldrich, catalog \#408727). Seven days after transfection, supernatants were harvested, clarified by centrifugation and subsequently incubated with Peptide M(Invivogen)/Protein G-coupled sepharose beads (Invivogen, catalog\# gel-pdm-5; GE healthcare, 17-0618-05) overnight at $4^{\circ} \mathrm{C}$. For dimers, antibodies were produced by transient transfection of Expi293F cells with heavy chain, light chain, and $\mathrm{J}$ chain expression plasmids at a 1:1:1 ratio. After five days, antibodies were harvested, filtered, incubated with Peptide M overnight and eluted.

\section{Separation of dimeric IgA from its monomeric form by size exclusion chromatography}

A pre-packed HiLoad 16/60 Superdex 200 pg (Cytiva, catalog \#28989335) on the NGC Quest 10 Plus Chromatography System by Bio-Rad was calibrated at room temperature using the HMW Gel Filtration Calibration Kit (Cytiva, catalog $\# 28403842$ ) and IgG. After equilibration of the column with PBS, each concentrated IgA preparation was applied onto the column using a $1 \mathrm{ml}$-loop at a flow rate of $0.5 \mathrm{ml} / \mathrm{min}$. Dimers of IgA1 or IgA2 were separated from monomers upon an isocratic elution with $70 \mathrm{ml}$ of PBS. The fractions were pooled, 
concentrated and evaluated by SDS-PAGE using 4-12\% BisTris Novex gels (GenScript catalog \#M00652) under reducing and non-reducing conditions followed by a Coomassie blue staining (Expedeon, catalog \#ISB1L).

\section{Microneutralization assay with authentic SARS-CoV-2}

Production of SARS-CoV-2 virus and the microneutralization assay were performed as described previously $(11,55)$. Vero E6 cells were seeded at $1 \times 10^{4}$ cells/well into 96 -well plates on the day before infection. IgA monomers and dimers were serially diluted (4-fold) in BA-1 medium, consisting of medium 199 (Lonza, Inc.) supplemented with 1\% BSA and 1x penicillin/streptomycin. The diluted samples were mixed with a constant amount of SARS-CoV-2 and incubated for 1 hour at $37^{\circ} \mathrm{C}$. The antibody-virus-mix was then directly applied to Vero E6 cells (MOI of $\sim 0.1 \mathrm{PFU} /$ cell; $n=3$ ) and incubated for 22 hours at $37^{\circ} \mathrm{C}$. Cells were subsequently fixed by adding an equal volume of $7 \%$ formaldehyde to the wells, followed by permeabilization with $0.1 \%$ Triton $\mathrm{X}-100$ for $10 \mathrm{~min}$. After extensive washing, cells were incubated for 1 hour at $37^{\circ} \mathrm{C}$ with blocking solution of $5 \%$ goat serum in PBS (catalog no. 005-000-121; Jackson ImmunoResearch). A rabbit polyclonal anti-SARS-CoV-2 nucleocapsid antibody (catalog no. GTX135357; GeneTex) was added to the cells at 1:1,000 dilution in blocking solution and incubated at $4^{\circ} \mathrm{C}$ overnight. Goat anti-rabbit AlexaFluor 594 (catalog no. A-11012; Life Technologies) was used as a secondary antibody at a dilution of 1:2000. Nuclei were stained with Hoechst 33342 (catalog no. 62249; Thermo Fisher Scientific) at a 1:1000 dilution. Images were acquired with a fluorescence microscope and analyzed using ImageXpress Micro XLS (Molecular Devices). All experiments involving SARS-CoV-2 were performed in a biosafety level 3 laboratory.

\section{Biolayer interferometry}

Biolayer interferometry assays were performed on the Octet Red instrument (ForteBio) at $30^{\circ} \mathrm{C}$ with shaking at 1000 rotations per minute. Epitope binding assays were performed with protein A biosensor (ForteBio 18-5010), following the manufacturer's protocol "classical sandwich assay". (1) Sensor check: sensors immersed $30 \mathrm{~s}$ in buffer alone (buffer ForteBio 18-1105). (2) Capture 1st Ab: sensors immersed 10 min with Ab1 at $40 \mu \mathrm{g} / \mathrm{mL}$. (3) Baseline: sensors immersed 30 $\mathrm{s}$ in buffer alone. (4) Blocking: sensors immersed 5 min with IgG isotype control at $50 \mu \mathrm{g} / \mathrm{mL}$. (6) Antigen association: sensors immersed 5 min with RBD at $100 \mu \mathrm{g} / \mathrm{mL}$. (7) Baseline: sensors immersed $30 \mathrm{~s}$ in buffer alone. (8) Association Ab2: sensors immersed 5 min with $\mathrm{Ab} 2$ at $40 \mu \mathrm{g} / \mathrm{mL}$. Curve fitting was performed using the Fortebio Octet Data analysis software (ForteBio). Affinity measurement: All measurements of RBD-biot binding to monomer IgA or RBD-biot binding to dimer IgA binding were corrected by subtracting the signal obtained from traces performed with RBD-biot but in absence of IgA. The kinetic analysis using high precision streptavidin biosensor (ForteBio 18-5118) was performed as follows: (1) baseline: $60 \mathrm{~s}$ immersion in buffer (kinetics buffer 10x ForteBio 18-1105). (2) loading: $200 \mathrm{~s}$ immersion in a solution with biotinylated RBD at $50 \mu \mathrm{g} / \mathrm{mL}$. (3) baseline: $200 \mathrm{~s}$ immersion in buffer. (4) Association: $300 \mathrm{~s}$ immersion in solution with IgA at $100 \mu \mathrm{M}$ or $50 \mu \mathrm{M}$ or $25 \mu \mathrm{M}$ (5) dissociation: $600 \mathrm{~s}$ immersion in buffer. Curve fitting was performed using the Fortebio Octet Data analysis software (ForteBio). Mean dissociation constant $\left(\mathrm{K}_{\mathrm{D}}\right)$ values were determined by averaging all three binding curves that matched the theoretical fit with an $R^{2}$ value $\geq 0.8$.

\section{Computational analyses of antibody sequences}

Antibody sequences were trimmed based on quality and annotated using Igblastn v1.14.0 (55) with IMGT domain delineation system. Annotation was performed systematically using Change-O toolkit v.0.4.5 (56). Heavy and light chains derived from the same cell were paired, and clonotypes were assigned based on their $\mathrm{V}$ and $\mathrm{J}$ genes using $\mathrm{R}$ and Perl scripts (Zenodo, DOI: 10.5281/zenodo.4296189). Nucleotide somatic hypermutation and CDR3 length were determined using inhouse $\mathrm{R}$ and Perl scripts. For somatic hypermutations, IGHV and IGLV nucleotide sequences were aligned against their closest germlines using Igblastn and the number of differences were considered nucleotide mutations. The average mutations for $\mathrm{V}$ genes was calculated by dividing the sum of all nucleotide mutations across all patients by the number of sequences used for the analysis. Hydrophobicity distribution comparisons were calculated as described in (11). The frequency distributions of human $\mathrm{V}$ genes in anti-SARS-CoV-2 antibodies from this study was compared to $131,284,220 \mathrm{IgH}$ and IgL sequences generated by (57) and downloaded from cAb-Rep (58), a database of human shared BCR clonotypes available at https://cab-rep.c2b2.columbia.edu/. Based on the 81 distinct $\mathrm{V}$ genes that make up the 1455 analyzed sequences from Ig repertoire of the three patients present in this study, we selected the IgH and IgL sequences from the database that are partially coded by the same $\mathrm{V}$ genes and counted them according to the constant region. The frequencies shown in fig. S5 are relative to the source and isotype analyzed. We used the two-sided binomial test to check whether the number of sequences belonging to a specific IgHV or IgLV gene in the repertoire is different according to the frequency of the same IgV gene in the database. Adjusted p-values were calculated using the false discovery rate (FDR) correction.

\section{Statistical analysis}

Statistical analyses were performed with GraphPad Prism 8.0 software. Normally distributed data were analyzed by two-sided $t$ test, and skewed data were analyzed by MannWhitney test. Comparisons of more than two groups were analyzed by one-way analysis of variance (ANOVA) with correction for multiple comparisons by Dunnett's method. Correlations were tested by Spearman's correlation 
coefficient. Statistical significance was defined as $\mathrm{P}<0.05$ unless stated otherwise. $P$ values smaller than 0.05 were considered statistically significant $\left({ }^{*} \mathrm{P}<0.05,{ }^{* *} \mathrm{P}<0.01,{ }^{* * *} \mathrm{P}<\right.$ 0.001 , and $\left.{ }^{* * * *} \mathrm{P}<0.0001\right)$. The data are shown as means and individual data points.

\section{SUPPLEMENTARY MATERIALS}

stm.sciencemag.org/cgi/content/full/scitranslmed.abf1555/DC1

Fig. S1. Age, duration of symptoms, and sex do not correlate with plasma IgA or IgG neutralization ability.

Fig. S2. Analysis of antibody somatic hypermutation.

Fig. S3. Analysis of antibody CDR3 length.

Fig. S4. Analysis of antibody CDR3 hydrophobicity.

Fig. S5. Frequency distributions of human V genes.

Fig. S6. Binding and neutralizing activity of anti-SARS-CoV-2 RBD IgA and IgM monomers.

Fig. S7. Biolayer interferometry experiment.

Fig. S8. Purification of Dimeric IgA by Size Exclusion Chromatography.

Fig. S9. Neutralizing activity of monoclonal monomeric and dimeric IgA antibodies.

Table S1. Inhibitory concentrations of monoclonal antibodies from isotype shared clones.

Table S2. Inhibitory concentrations of monoclonal IgA monomers and dimers.

Data File S1. Sequences of anti-SARS-CoV-2 antibodies

Data File S2. Sequences of antibodies from isotype shared clones

Data File S3. Sequences of cloned recombinant antibodies

Data File S4. Effective and inhibitory concentrations of monoclonal antibodies

Data File S5. Primers

Data File S6. Raw data for graphs with $\mathrm{n}<20$.

\section{REFERENCES AND NOTES}

1. A. C. Walls, Y. J. Park, M. A. Tortorici, A. Wall, A. T. McGuire, D. Veesler, Structure, Function, and Antigenicity of the SARS-CoV-2 Spike Glycoprotein. Cell 181, 281292.e6 (2020). doi:10.1016/i.cell.2020.02.058 Medline

2. P. Zhou, X. L. Yang, X. G. Wang, B. Hu, L. Zhang, W. Zhang, H. R. Si, Y. Zhu, B. Li, C. L. Huang, H. D. Chen, J. Chen, Y. Luo, H. Guo, R. D. Jiang, M. Q. Liu, Y. Chen, X. R. Shen, X. Wang, X. S. Zheng, K. Zhao, Q. J. Chen, F. Deng, L. L. Liu, B. Yan, F. X. Zhan, Y. Y. Wang, G. F. Xiao, Z. L. Shi, A pneumonia outbreak associated with a new coronavirus of probable bat origin. Nature 579, 270-273 (2020). doi:10.1038/s41586-020-2012-7 Medline

3. M. Hoffmann, H. Kleine-Weber, S. Schroeder, N. Krüger, T. Herrler, S. Erichsen, T. S. Schiergens, G. Herrler, N. H. Wu, A. Nitsche, M. A. Müller, C. Drosten, S. Pöhlmann, SARS-CoV-2 Cell Entry Depends on ACE2 and TMPRSS2 and Is Blocked by a Clinically Proven Protease Inhibitor. Cell 181, 271-280.e8 (2020). doi:10.1016/i.cell.2020.02.052 Medline

4. R. Lu, X. Zhao, J. Li, P. Niu, B. Yang, H. Wu, W. Wang, H. Song, B. Huang, N. Zhu, Y. Bi, X. Ma, F. Zhan, L. Wang, T. Hu, H. Zhou, Z. Hu, W. Zhou, L. Zhao, J. Chen, Y. Meng, J. Wang, Y. Lin, J. Yuan, Z. Xie, J. Ma, W. J. Liu, D. Wang, W. Xu, E. C. Holmes, G. F. Gao, G. Wu, W. Chen, W. Shi, W. Tan, Genomic characterisation and epidemiology of 2019 novel coronavirus: Implications for virus origins and receptor binding. Lancet 395, 565-574 (2020). doi:10.1016/S01406736(20)30251-8 Medline

5. D. Wrapp, N. Wang, K. S. Corbett, J. A. Goldsmith, C. L. Hsieh, O. Abiona, B. S. Graham, J. S. McLellan, Cryo-EM structure of the 2019-nCoV spike in the prefusion conformation. Science 367, 1260-1263 (2020). doi:10.1126/science.abb2507 Medline

6. J. Lan, J. Ge, J. Yu, S. Shan, H. Zhou, S. Fan, Q. Zhang, X. Shi, Q. Wang, L. Zhang, X. Wang, Structure of the SARS-CoV-2 spike receptor-binding domain bound to the ACE2 receptor. Nature 581, 215-220 (2020). doi:10.1038/s41586-020-2180-5 Medline

7. A. O. Hassan, N. M. Kafai, I. P. Dmitriev, J. M. Fox, B. K. Smith, I. B. Harvey, R. E. Chen, E. S. Winkler, A. W. Wessel, J. B. Case, E. Kashentseva, B. T. McCune, A. L. Bailey, H. Zhao, L. A. VanBlargan, Y. N. Dai, M. Ma, L. J. Adams, S. Shrihari, J. E. Danis, L. E. Gralinski, Y. J. Hou, A. Schäfer, A. S. Kim, S. P. Keeler, D. Weiskopf, R. S. Baric, M. J. Holtzman, D. H. Fremont, D. T. Curiel, M. S. Diamond, A Single-Dose Intranasal ChAd Vaccine Protects Upper and Lower Respiratory Tracts against
SARS-CoV-2. Cell 183, 169-184.e13 (2020). doi:10.1016/i.cell.2020.08.026 Medline

8. B. J. Underdown, J. M. Schiff, Immunoglobulin A: Strategic defense initiative at the mucosal surface. Annu. Rev. Immunol. 4, 389-417 (1986). doi:10.1146/annureviy. 04.040186.002133 Medline

9. M. E. Koshland, The coming of age of the immunoglobulin J chain. Annu. Rev. Immunol. 3, 425-453 (1985). doi:10.1146/annurev.iy.03.040185.002233 Medline

10. O. Pabst, New concepts in the generation and functions of IgA. Nat. Rev. Immunol. 12, 821-832 (2012). doi:10.1038/nri3322 Medline

11. D. F. Robbiani, C. Gaebler, F. Muecksch, J. C. C. Lorenzi, Z. Wang, A. Cho, M. Agudelo, C. O. Barnes, A. Gazumyan, S. Finkin, T. Hägglöf, T. Y. Oliveira, C. Viant, A. Hurley, H. H. Hoffmann, K. G. Millard, R. G. Kost, M. Cipolla, K. Gordon, F. Bianchini, S. T. Chen, V. Ramos, R. Patel, J. Dizon, I. Shimeliovich, P. Mendoza, H. Hartweger, L. Nogueira, M. Pack, J. Horowitz, F. Schmidt, Y. Weisblum, E. Michailidis, A. W. Ashbrook, E. Waltari, J. E. Pak, K. E. Huey-Tubman, N. Koranda, P. R. Hoffman, A. P. West Jr., C. M. Rice, T. Hatziioannou, P. J. Bjorkman, P. D. Bieniasz, M. Caskey, M. C. Nussenzweig, Convergent antibody responses to SARS-CoV-2 in convalescent individuals. Nature 584, 437-442 (2020). doi:10.1038/s41586-020-2456-9 Medline

12. F. Wu, M. Liu, A. Wang, L. Lu, Q. Wang, C. Gu, J. Chen, Y. Wu, S. Xia, Y. Ling, Y. Zhang, J. Xun, R. Zhang, Y. Xie, S. Jiang, T. Zhu, H. Lu, Y. Wen, J. Huang, Evaluating the association of clinical characteristics with neutralizing antibody levels in patients who have recovered from mild COVID-19 in Shanghai, China. JAMA Intern. Med. 180, 1356-1362 (2020). doi:10.1001/jamainternmed.2020.4616 Medline

13. B. Ju, Q. Zhang, J. Ge, R. Wang, J. Sun, X. Ge, J. Yu, S. Shan, B. Zhou, S. Song, X. Tang, J. Yu, J. Lan, J. Yuan, H. Wang, J. Zhao, S. Zhang, Y. Wang, X. Shi, L. Liu, J. Zhao, X. Wang, Z. Zhang, L. Zhang, Human neutralizing antibodies elicited by SARS-CoV-2 infection. Nature 584, 115-119 (2020). doi:10.1038/s41586-0202380-z Medline

14. P. J. M. Brouwer, T. G. Caniels, K. van der Straten, J. L. Snitselaar, Y. Aldon, S. Bangaru, J. L. Torres, N. M. A. Okba, M. Claireaux, G. Kerster, A. E. H. Bentlage, M. M. van Haaren, D. Guerra, J. A. Burger, E. E. Schermer, K. D. Verheul, N. van der Velde, A. van der Kooi, J. van Schooten, M. J. van Breemen, T. P. L. Bijl, K. Sliepen, A. Aartse, R. Derking, I. Bontjer, N. A. Kootstra, W. J. Wiersinga, G. Vidarsson, B. L. Haagmans, A. B. Ward, G. J. de Bree, R. W. Sanders, M. J. van Gils, Potent neutralizing antibodies from COVID-19 patients define multiple targets of vulnerability. Science 369, 643-650 (2020). doi:10.1126/science.abc5902 Medline

15. L. Liu, P. Wang, M. S. Nair, J. Yu, M. Rapp, Q. Wang, Y. Luo, J. F. Chan, V. Sahi, A. Figueroa, X. V. Guo, G. Cerutti, J. Bimela, J. Gorman, T. Zhou, Z. Chen, K. Y. Yuen, P. D. Kwong, J. G. Sodroski, M. T. Yin, Z. Sheng, Y. Huang, L. Shapiro, D. D. Ho, Potent neutralizing antibodies against multiple epitopes on SARS-CoV-2 spike. Nature 584, 450-456 (2020). doi:10.1038/s41586-020-2571-7 Medline

16. Y. Wu, F. Wang, C. Shen, W. Peng, D. Li, C. Zhao, Z. Li, S. Li, Y. Bi, Y. Yang, Y. Gong, H. Xiao, Z. Fan, S. Tan, G. Wu, W. Tan, X. Lu, C. Fan, Q. Wang, Y. Liu, C. Zhang, J. Qi, G. F. Gao, F. Gao, L. Liu, A noncompeting pair of human neutralizing antibodies block COVID-19 virus binding to its receptor ACE2. Science 368, 1274-1278 (2020). doi:10.1126/science.abc2241 Medline

17. T. F. Rogers, F. Zhao, D. Huang, N. Beutler, A. Burns, W. T. He, O. Limbo, C. Smith, G. Song, J. Woehl, L. Yang, R. K. Abbott, S. Callaghan, E. Garcia, J. Hurtado, M. Parren, L. Peng, S. Ramirez, J. Ricketts, M. J. Ricciardi, S. A. Rawlings, N. C. Wu, M. Yuan, D. M. Smith, D. Nemazee, J. R. Teijaro, J. E. Voss, I. A. Wilson, R. Andrabi, B. Briney, E. Landais, D. Sok, J. G. Jardine, D. R. Burton, Isolation of potent SARSCoV-2 neutralizing antibodies and protection from disease in a small animal model. Science 369, 956-963 (2020). Medline

18. S. J. Zost, P. Gilchuk, J. B. Case, E. Binshtein, R. E. Chen, J. P. Nkolola, A. Schäfer, J. X. Reidy, A. Trivette, R. S. Nargi, R. E. Sutton, N. Suryadevara, D. R. Martinez, L. E. Williamson, E. C. Chen, T. Jones, S. Day, L. Myers, A. O. Hassan, N. M. Kafai, E. S. Winkler, J. M. Fox, S. Shrihari, B. K. Mueller, J. Meiler, A. Chandrashekar, N. B. Mercado, J. J. Steinhardt, K. Ren, Y. M. Loo, N. L. Kallewaard, B. T. McCune, S. P. Keeler, M. J. Holtzman, D. H. Barouch, L. E. Gralinski, R. S. Baric, L. B. Thackray, M. S. Diamond, R. H. Carnahan, J. E. Crowe Jr., Potently neutralizing and protective human antibodies against SARS-CoV-2. Nature 584, 443-449 (2020). doi:10.1038/s41586-020-2548-6 Medline 
19. A. Baum, D. Ajithdoss, R. Copin, A. Zhou, K. Lanza, N. Negron, M. Ni, Y. Wei, K. Mohammadi, B. Musser, G. S. Atwal, A. Oyejide, Y. Goez-Gazi, J. Dutton, E. Clemmons, H. M. Staples, C. Bartley, B. Klaffke, K. Alfson, M. Gazi, O. Gonzalez, E. Dick Jr., R. Carrion Jr., L. Pessaint, M. Porto, A. Cook, R. Brown, V. Ali, J. Greenhouse, T. Taylor, H. Andersen, M. G. Lewis, N. Stahl, A. J. Murphy, G. D. Yancopoulos, C. A. Kyratsous, REGN-COV2 antibodies prevent and treat SARSCoV-2 infection in rhesus macaques and hamsters. Science 370, 1110-1115 (2020). doi:10.1126/science.abe2402 Medline

20. W. F. Garcia-Beltran, E. C. Lam, M. G. Astudillo, D. Yang, T. E. Miller, J. Feldman, B. M. Hauser, T. M. Caradonna, K. L. Clayton, A. D. Nitido, M. R. Murali, G. Alter, R. C. Charles, A. Dighe, J. A. Branda, J. K. Lennerz, D. Lingwood, A. G. Schmidt, A. J. lafrate, A. B. Balazs, COVID-19 neutralizing antibodies predict disease severity and survival. medRxiv 2020.10.15.20213512 (2020). Medline

21. C. Atyeo, S. Fischinger, T. Zohar, M. D. Slein, J. Burke, C. Loos, D. J. McCulloch, K. L. Newman, C. Wolf, J. Yu, K. Shuey, J. Feldman, B. M. Hauser, T. Caradonna, A. G. Schmidt, T. J. Suscovich, C. Linde, Y. Cai, D. Barouch, E. T. Ryan, R. C. Charles, D. Lauffenburger, H. Chu, G. Alter, Distinct Early Serological Signatures Track with SARS-CoV-2 Survival. Immunity 53, 524-532.e4 (2020). doi:10.1016/i.immuni.2020.07.020 Medline

22. S. F. Lumley, D. O'Donnell, N. E. Stoesser, P. C. Matthews, A. Howarth, S. B. Hatch, B. D. Marsden, S. Cox, T. James, F. Warren, L. J. Peck, T. G. Ritter, Z. de Toledo, L. Warren, D. Axten, R. J. Cornall, E. Y. Jones, D. I. Stuart, G. Screaton, D. Ebner, S. Hoosdally, M. Chand, D. W. Crook, A.-M. O'Donnell, C. P. Conlon, K. B. Pouwels, A. S. Walker, T. E. Peto, S. Hopkins, T. M. Walker, K. Jeffery, D. W. Eyre, Antibodies to SARS-CoV-2 are associated with protection against reinfection. medRxiv, 2020.2011.2018.20234369 (2020).

23. H. Ma, W. Zeng, H. He, D. Zhao, D. Jiang, P. Zhou, L. Cheng, Y. Li, X. Ma, T. Jin, Serum IgA, IgM, and IgG responses in COVID-19. Cell. Mol. Immunol. 17, 773-775 (2020). doi:10.1038/s41423-020-0474-z Medline

24. D. Sterlin, A. Mathian, M. Miyara, A. Mohr, F. Anna, L. Claer, P. Quentric, J. Fadlallah, P. Ghillani, C. Gunn, R. Hockett, S. Mudumba, A. Guihot, C.-E. Luyt, J. Mayaux, A. Beurton, S. Fourati, J.-M. Lacorte, H. Yssel, C. Parizot, K. Dorgham, P. Charneau, Z. Amoura, G. Gorochov, IgA dominates the early neutralizing antibody response to SARS-CoV-2. medRxiv, 2020.2006.2010.20126532 (2020).

25. H. Q. Yu, B. Q. Sun, Z. F. Fang, J. C. Zhao, X. Y. Liu, Y. M. Li, X. Z. Sun, H. F. Liang, B. Zhong, Z. F. Huang, P. Y. Zheng, L. F. Tian, H. Q. Qu, D. C. Liu, E. Y. Wang, X. J. Xiao, S. Y. Li, F. Ye, L. Guan, D. S. Hu, H. Hakonarson, Z. G. Liu, N. S. Zhong, Distinct features of SARS-CoV-2-specific IgA response in COVID-19 patients. Eur. Respir. J. 56, 2001526 (2020). doi:10.1183/13993003.01526-2020 Medline

26. J. Seow, C. Graham, B. Merrick, S. Acors, S. Pickering, K. J. A. Steel, O. Hemmings, A. O'Byrne, N. Kouphou, R. P. Galao, G. Betancor, H. D. Wilson, A. W. Signell, H. Winstone, C. Kerridge, I. Huettner, J. M. Jimenez-Guardeño, M. J. Lista, N. Temperton, L. B. Snell, K. Bisnauthsing, A. Moore, A. Green, L. Martinez, B. Stokes, J. Honey, A. Izquierdo-Barras, G. Arbane, A. Patel, M. K. I. Tan, L. O'Connell, G. O'Hara, E. MacMahon, S. Douthwaite, G. Nebbia, R. Batra, R. Martinez-Nunez, M. Shankar-Hari, J. D. Edgeworth, S. J. D. Neil, M. H. Malim, K. J. Doores, Longitudinal observation and decline of neutralizing antibody responses in the three months following SARS-CoV-2 infection in humans. Nat. Microbiol. 5, 1598-1607 (2020). doi:10.1038/s41564-020-00813-8 Medline

27. T. Suzuki, A. Kawaguchi, A. Ainai, S. Tamura, R. Ito, P. Multihartina, V. Setiawaty, K. N. Pangesti, T. Odagiri, M. Tashiro, H. Hasegawa, Relationship of the quaternary structure of human secretory lgA to neutralization of influenza virus. Proc. Natl. Acad. Sci. U.S.A. 112, 7809-7814 (2015). doi:10.1073/pnas.1503885112 Medline

28. Y. Terauchi, K. Sano, A. Ainai, S. Saito, Y. Taga, K. Ogawa-Goto, S. I. Tamura, T. Odagiri, M. Tashiro, M. Fujieda, T. Suzuki, H. Hasegawa, IgA polymerization contributes to efficient virus neutralization on human upper respiratory mucosa after intranasal inactivated influenza vaccine administration. Hum. Vaccin. Immunother. 14, 1351-1361 (2018). doi:10.1080/21645515.2018.1438791 Medline

29. S. Saito, K. Sano, T. Suzuki, A. Ainai, Y. Taga, T. Ueno, K. Tabata, K. Saito, Y. Wada, Y. Ohara, H. Takeyama, T. Odagiri, T. Kageyama, K. Ogawa-Goto, P. Multihartina, V. Setiawaty, K. N. A. Pangesti, H. Hasegawa, IgA tetramerization improves target breadth but not peak potency of functionality of anti-influenza virus broadly neutralizing antibody. PLOS Pathog. 15, e1007427 (2019). doi:10.1371/journal.ppat.1007427 Medline
30. R. D. Astronomo, S. Santra, L. Ballweber-Fleming, K. G. Westerberg, L. Mach, T. Hensley-McBain, L. Sutherland, B. Mildenberg, G. Morton, N. L. Yates, G. J. Mize, J. Pollara, F. Hladik, C. Ochsenbauer, T. N. Denny, R. Warrier, S. Rerks-Ngarm, P. Pitisuttithum, S. Nitayapan, J. Kaewkungwal, G. Ferrari, G. M. Shaw, S. M. Xia, H. X. Liao, D. C. Montefiori, G. D. Tomaras, B. F. Haynes, J. M. McElrath, Neutralization Takes Precedence Over IgG or IgA Isotype-related Functions in Mucosal HIV-1 Antibody-mediated Protection. EBioMedicine 14, 97-111 (2016). doi:10.1016/i.ebiom.2016.11.024 Medline

31. X. Chi, R. Yan, J. Zhang, G. Zhang, Y. Zhang, M. Hao, Z. Zhang, P. Fan, Y. Dong, Y. Yang, Z. Chen, Y. Guo, J. Zhang, Y. Li, X. Song, Y. Chen, L. Xia, L. Fu, L. Hou, J. Xu, C. Yu, J. Li, Q. Zhou, W. Chen, A neutralizing human antibody binds to the $\mathrm{N}$ terminal domain of the Spike protein of SARS-CoV-2. Science 369, 650-655 (2020). doi:10.1126/science.abc6952 Medline

32. Y. Cao, B. Su, X. Guo, W. Sun, Y. Deng, L. Bao, Q. Zhu, X. Zhang, Y. Zheng, C. Geng, X. Chai, R. He, X. Li, Q. Lv, H. Zhu, W. Deng, Y. Xu, Y. Wang, L. Qiao, Y. Tan, L. Song, G. Wang, X. Du, N. Gao, J. Liu, J. Xiao, X. D. Su, Z. Du, Y. Feng, C. Qin, C. Qin, R. Jin, X. S. Xie, Potent Neutralizing Antibodies against SARS-CoV-2 Identified by HighThroughput Single-Cell Sequencing of Convalescent Patients' B Cells. Cell 182 73-84.e16 (2020). doi:10.1016/i.cell.2020.05.025 Medline

33. C. Kreer, M. Zehner, T. Weber, M. S. Ercanoglu, L. Gieselmann, C. Rohde, S. Halwe, M. Korenkov, P. Schommers, K. Vanshylla, V. Di Cristanziano, H. Janicki, R. Brinker, A. Ashurov, V. Krähling, A. Kupke, H. Cohen-Dvashi, M. Koch, J. M. Eckert, S. Lederer, N. Pfeifer, T. Wolf, M. J. G. T. Vehreschild, C. Wendtner, R. Diskin, H. Gruell, S. Becker, F. Klein, Longitudinal Isolation of Potent Near-Germline SARSCoV-2-Neutralizing Antibodies from COVID-19 Patients. Cell 182, 843-854.e12 (2020). doi:10.1016/j.cell.2020.06.044 Medline

34. F. Schmidt, Y. Weisblum, F. Muecksch, H. H. Hoffmann, E. Michailidis, J. C. C. Lorenzi, P. Mendoza, M. Rutkowska, E. Bednarski, C. Gaebler, M. Agudelo, A. Cho, Z. Wang, A. Gazumyan, M. Cipolla, M. Caskey, D. F. Robbiani, M. C. Nussenzweig, C. M. Rice, T. Hatziioannou, P. D. Bieniasz, Measuring SARS-CoV-2 neutralizing antibody activity using pseudotyped and chimeric viruses. J. Exp. Med. 217, e20201181 (2020). doi:10.1084/jem.20201181 Medline

35. R. Shi, C. Shan, X. Duan, Z. Chen, P. Liu, J. Song, T. Song, X. Bi, C. Han, L. Wu, G. Gao, X. Hu, Y. Zhang, Z. Tong, W. Huang, W. J. Liu, G. Wu, B. Zhang, L. Wang, J. Qi, H. Feng, F. S. Wang, Q. Wang, G. F. Gao, Z. Yuan, J. Yan, A human neutralizing antibody targets the receptor-binding site of SARS-CoV-2. Nature 584, 120-124 (2020). doi:10.1038/s41586-020-2381-y Medline

36. E. Seydoux, L. J. Homad, A. J. MacCamy, K. R. Parks, N. K. Hurlburt, M. F. Jennewein, N. R. Akins, A. B. Stuart, Y. H. Wan, J. Feng, R. E. Whaley, S. Singh, M. Boeckh, K. W. Cohen, M. J. McElrath, J. A. Englund, H. Y. Chu, M. Pancera, A. T. McGuire, L. Stamatatos, Analysis of a SARS-CoV-2-Infected Individual Reveals Development of Potent Neutralizing Antibodies with Limited Somatic Mutation. Immunity 53, 98-105.e5 (2020). doi:10.1016/j.immuni.2020.06.001 Medline

37. J. F. Scheid, H. Mouquet, N. Feldhahn, M. S. Seaman, K. Velinzon, J. Pietzsch, R. G. Ott, R. M. Anthony, H. Zebroski, A. Hurley, A. Phogat, B. Chakrabarti, Y. Li, M. Connors, F. Pereyra, B. D. Walker, H. Wardemann, D. Ho, R. T. Wyatt, J. R. Mascola, J. V. Ravetch, M. C. Nussenzweig, Broad diversity of neutralizing antibodies isolated from memory B cells in HIV-infected individuals. Nature 458, 636-640 (2009). doi:10.1038/nature07930 Medline

38. Q. Wang, E. Michailidis, Y. Yu, Z. Wang, A. M. Hurley, D. A. Oren, C. T. Mayer, A. Gazumyan, Z. Liu, Y. Zhou, T. Schoofs, K. H. Yao, J. P. Nieke, J. Wu, Q. Jiang, C. Zou, M. Kabbani, C. Quirk, T. Oliveira, K. Chhosphel, Q. Zhang, W. M. Schneider, C. Jahan, T. Ying, J. Horowitz, M. Caskey, M. Jankovic, D. F. Robbiani, Y. Wen, Y. P. de Jong, C. M. Rice, M. C. Nussenzweig, A Combination of Human Broadly Neutralizing Antibodies against Hepatitis B Virus HBsAg with Distinct Epitopes Suppresses Escape Mutations. Cell Host Microbe 28, 335-349.e6 (2020). doi:10.1016/i.chom.2020.05.010 Medline

39. G. D. Victora, M. C. Nussenzweig, Germinal centers. Annu. Rev. Immunol. 30, 429457 (2012). doi:10.1146/annurev-immunol-020711-075032 Medline

40. C. O. Barnes, A. P. West Jr., K. E. Huey-Tubman, M. A. G. Hoffmann, N. G. Sharaf, P. R. Hoffman, N. Koranda, H. B. Gristick, C. Gaebler, F. Muecksch, J. C. C. Lorenzi, S. Finkin, T. Hägglöf, A. Hurley, K. G. Millard, Y. Weisblum, F. Schmidt, T. Hatziioannou, P. D. Bieniasz, M. Caskey, D. F. Robbiani, M. C. Nussenzweig, P. J. Bjorkman, Structures of Human Antibodies Bound to SARS-CoV-2 Spike Reveal Common Epitopes and Recurrent Features of Antibodies. Cell 182, 828-842.e16 
(2020). doi:10.1016/i.cell.2020.06.025 Medline

41. M. Yuan, H. Liu, N. C. Wu, C. D. Lee, X. Zhu, F. Zhao, D. Huang, W. Yu, Y. Hua, H. Tien, T. F. Rogers, E. Landais, D. Sok, J. G. Jardine, D. R. Burton, I. A. Wilson, Structural basis of a shared antibody response to SARS-CoV-2. Science 369, 1119-1123 (2020). doi:10.1126/science.abd2321 Medline

42. M. Yuan, N. C. Wu, X. Zhu, C. D. Lee, R. T. Y. So, H. Lv, C. K. P. Mok, I. A. Wilson, A highly conserved cryptic epitope in the receptor binding domains of SARS-CoV-2 and SARS-CoV. Science 368, 630-633 (2020). doi:10.1126/science.abb7269 Medline

43. S. A. Plotkin, Correlates of protection induced by vaccination. Clin. Vaccine Immunol. 17, 1055-1065 (2010). doi:10.1128/CVI.00131-10 Medline

44. K. Chen, G. Magri, E. K. Grasset, A. Cerutti, Rethinking mucosal antibody responses: IgM, IgG and IgD join IgA. Nat. Rev. Immunol. 20, 427-441 (2020). doi:10.1038/s41577-019-0261-1 Medline

45. C. Viant, G. H. J. Weymar, A. Escolano, S. Chen, H. Hartweger, M. Cipolla, A. Gazumyan, M. C. Nussenzweig, Antibody Affinity Shapes the Choice between Memory and Germinal Center B Cell Fates. Cell 183, 1298-1311.e11 (2020). doi:10.1016/i.cell.2020.09.063 Medline

46. A. O. Hassan, N. M. Kafai, I. P. Dmitriev, J. M. Fox, B. K. Smith, I. B. Harvey, R. E. Chen, E. S. Winkler, A. W. Wessel, J. B. Case, E. Kashentseva, B. T. McCune, A. L. Bailey, H. Zhao, L. A. VanBlargan, Y.-N. Dai, M. Ma, L. J. Adams, S. Shrihari, J. E. Danis, L. E. Gralinski, Y. J. Hou, A. Schäfer, A. S. Kim, S. P. Keeler, D. Weiskopf, R. S. Baric, M. J. Holtzman, D. H. Fremont, D. T. Curiel, M. S. Diamond, A single-dose intranasal ChAd vaccine protects upper and lower respiratory tracts against SARS-CoV-2. Cell 183, 169-184.e13 (2020). doi:10.1016/i.cell.2020.08.026 Medline

47. K. Eriksson, M. Quiding-Järbrink, J. Osek, A. Möller, S. Björk, J. Holmgren, C. Czerkinsky, Specific-antibody-secreting cells in the rectums and genital tracts of nonhuman primates following vaccination. Infect. Immun. 66, 5889-5896 (1998), doi:10.1128/IAl.66.12.5889-5896.1998 Medline

48. A. Kantele, M. Häkkinen, Z. Moldoveanu, A. Lu, E. Savilahti, R. D. Alvarez, S. Michalek, J. Mestecky, Differences in immune responses induced by oral and rectal immunizations with Salmonella typhi Ty21a: Evidence for compartmentalization within the common mucosal immune system in humans. Infect. Immun. 66, 5630-5635 (1998). doi:10.1128//Al.66.12.5630-5635.1998 Medline

49. S. Hopkins, J. P. Kraehenbuhl, F. Schödel, A. Potts, D. Peterson, P. de Grandi, D. Nardelli-Haefliger, A recombinant Salmonella typhimurium vaccine induces local immunity by four different routes of immunization. Infect. Immun. 63, 3279-3286 (1995). doi:10.1128/IAl.63.9.3279-3286.1995 Medline

50. A. Grifoni, D. Weiskopf, S. I. Ramirez, J. Mateus, J. M. Dan, C. R. Moderbacher, S. A. Rawlings, A. Sutherland, L. Premkumar, R. S. Jadi, D. Marrama, A. M. de Silva, A. Frazier, A. F. Carlin, J. A. Greenbaum, B. Peters, F. Krammer, D. M. Smith, S. Crotty, A. Sette, Targets of T Cell Responses to SARS-CoV-2 Coronavirus in Humans with COVID-19 Disease and Unexposed Individuals. Cell 181, 14891501.e15 (2020). doi:10.1016/i.cell.2020.05.015 Medline

51. F. Amanat, D. Stadlbauer, S. Strohmeier, T. H. O. Nguyen, V. Chromikova, M. McMahon, K. Jiang, G. A. Arunkumar, D. Jurczyszak, J. Polanco, M. BermudezGonzalez, G. Kleiner, T. Aydillo, L. Miorin, D. S. Fierer, L. A. Lugo, E. M. Kojic, J. Stoever, S. T. H. Liu, C. Cunningham-Rundles, P. L. Felgner, T. Moran, A. GarcíaSastre, D. Caplivski, A. C. Cheng, K. Kedzierska, O. Vapalahti, J. M. Hepojoki, V. Simon, F. Krammer, A serological assay to detect SARS-CoV-2 seroconversion in humans. Nat. Med. 26, 1033-1036 (2020). doi:10.1038/s41591-020-0913-5 Medline

52. T. Tiller, E. Meffre, S. Yurasov, M. Tsuiji, M. C. Nussenzweig, H. Wardemann, Efficient generation of monoclonal antibodies from single human $\mathrm{B}$ cells by single cell RT-PCR and expression vector cloning. J. Immunol. Methods 329, 112-124 (2008). doi:10.1016/i.jim.2007.09.017 Medline

53. L. von Boehmer, C. Liu, S. Ackerman, A. D. Gitlin, Q. Wang, A. Gazumyan, M. C. Nussenzweig, Sequencing and cloning of antigen-specific antibodies from mouse memory B cells. Nat. Protoc. 11, 1908-1923 (2016). doi:10.1038/nprot.2016.102 Medline

54. D. F. Robbiani, L. Bozzacco, J. R. Keeffe, R. Khouri, P. C. Olsen, A. Gazumyan, D. Schaefer-Babajew, S. Avila-Rios, L. Nogueira, R. Patel, S. A. Azzopardi, L. F. K. Uhl, M. Saeed, E. E. Sevilla-Reyes, M. Agudelo, K. H. Yao, J. Golijanin, H. B. Gristick, Y.
E. Lee, A. Hurley, M. Caskey, J. Pai, T. Oliveira, E. A. Wunder Jr., G. Sacramento, N. Nery Jr., C. Orge, F. Costa, M. G. Reis, N. M. Thomas, T. Eisenreich, D. M. Weinberger, A. R. P. de Almeida, A. P. West Jr., C. M. Rice, P. J. Bjorkman, G. Reyes-Teran, A. I. Ko, M. R. MacDonald, M. C. Nussenzweig, Recurrent Potent Human Neutralizing Antibodies to Zika Virus in Brazil and Mexico. Cell 169, 597609.e11 (2017). doi:10.1016/i.cell.2017.04.024 Medline

55. J. Ye, N. Ma, T. L. Madden, J. M. Ostell, IgBLAST: An immunoglobulin variable domain sequence analysis tool. Nucleic Acids Res. 41 (W1), W34-40 (2013). doi:10.1093/nar/gkt382 Medline

56. N. T. Gupta, J. A. Vander Heiden, M. Uduman, D. Gadala-Maria, G. Yaari, S. H. Kleinstein, Change-0: A toolkit for analyzing large-scale B cell immunoglobulin repertoire sequencing data. Bioinformatics 31, 3356-3358 (2015). doi:10.1093/bioinformatics/btv359 Medline

57. C. Soto, R. G. Bombardi, A. Branchizio, N. Kose, P. Matta, A. M. Sevy, R. S. Sinkovits, P. Gilchuk, J. A. Finn, J. E. Crowe Jr., High frequency of shared clonotypes in human B cell receptor repertoires. Nature 566, 398-402 (2019). doi:10.1038/s41586-019-0934-8 Medline

58. Y. Guo, K. Chen, P. D. Kwong. L. Shapiro, Z. Sheng, cAb-Rep: A Database of Curated Antibody Repertoires for Exploring Antibody Diversity and Predicting Antibody Prevalence. Front. Immunol. 10, 2365 (2019). doi:10.3389/fimmu.2019.02365 Medline

59. C. O. Barnes, A. P. West Jr., K. E. Huey-Tubman, M. A. G. Hoffmann, N. G. Sharaf, P. R. Hoffman, N. Koranda, H. B. Gristick, C. Gaebler, F. Muecksch, J. C. Cetrulo Lorenzi, S. Finkin, T. Hagglof, A. Hurley, K. G. Millard, Y. Weisblum, F. Schmidt, T. Hatziioannou, P. D. Bieniasz, M. Caskey, D. F. Robbiani, M. C. Nussenzweig, P. J. Bjorkman, Structures of human antibodies bound to SARS-CoV-2 spike reveal common epitopes and recurrent features of antibodies. bioRxiv 182, 828-842.e16 (2020). doi:10.1016/j.cell.2020.06.025 Medline

Acknowledgments: We thank all study participants who devoted time to our research, Barry Coller and Sarah Schlesinger, the Rockefeller University Hospital Clinical Research Support Office and nursing staff, Ivo Lorenz, and the Tri-I TDI antibody team for help with biolayer inferometry measurements. We also thank all members of the M.C.N. laboratory for helpful discussions and Maša Jankovic for laboratory support. Funding: This work was supported by NIH grant P01Al138398-S1 and 2U1 9Al111825 to M.C.N. and C.M.R.; George Mason University Fast Grants to D.F.R. and C.M.R., 3 R01-AI091707-10S1 to C.M.R.; The G. Harold and Leila Y. Mathers Charitable Foundation to C.M.R.; European ATAC consortium (EC 101003650) to D.F.R. Robert S. Wennett Post-Doctoral Fellowship to C.G., in part by the National Center for Advancing Translational Sciences (National Institutes of Health Clinical and Translational Science Award program, grant UL1 TR001866) and by the Shapiro-Silverberg Fund for the Advancement of Translational Research. P.D.B. and M.C.N. are Howard Hughes Medical Institute Investigators. Author contributions: Z.W., J.C.C.L., F.M., S.F. and M.C.N. conceived, designed and analyzed the experiments. Z.W., J.C.C.L., F.M., S.F., C.V., M.C., H.-H.H. L.N. and E.M. carried out all experiments. D.F.R., M. Caskey and C.G. designed clinical protocols. M.C., A.G. and D.O. produced antibodies. T.Y.O., and V.R. performed bioinformatic analysis. C.M.R., T.M. and P.D.B. helped to design the experiments. Z.W., J.C.C.L., F.M., S.F. and M.C.N. wrote the manuscript with input from all co-authors. Competing interests: In connection with this work, The Rockefeller University has filed a provisional patent application "Broadly neutralizing anti-SARS-CoV-2 antibodies and methods of use thereof" (\#US 63/016,569) on which D.F.R. and M.C.N. are inventors. M.C.N. is on the scientific advisory board of CellDex Therapeutics and Frontier Biosciences. Data and materials availability: All data associated with this study are in the paper or supplementary materials. The raw sequencing data associated with Fig. 4 has been deposited at GenBank (MW292809 MW293718). This study uses data from a database of human shared BCR clonotypes "https://cabrep.c2b2.columbia.edu/home/", and from "cAb-Rep: A Database of Curated Antibody Repertoires for Exploring Antibody Diversity and Predicting Antibody Prevalence' and 'High frequency of shared clonotypes in human B cell receptor repertoires'. Computer code to process the antibody sequences are available at Zenodo (DOI: 10.5281/zenodo.4296189). All SARSCoV-2 antibodies reported are available from Michel Nussenzweig under a standard Uniform Biological Material Transfer Agreement. This work is licensed under a Creative Commons Attribution 4.0 International (CC BY 4.0) license, 
which permits unrestricted use, distribution, and reproduction in any medium, provided the original work is properly cited. To view a copy of this license, visit https://creativecommons.org/licenses/by/4.0/. This license does not apply to figures/photos/artwork or other content included in the article that is credited to a third party; obtain authorization from the rights holder before using this material.

Submitted 7 October 2020

Resubmitted 22 October 2020

Accepted 30 November 2020

Published First Release 7 December 2020

10.1126/scitransImed.abf1555 
A

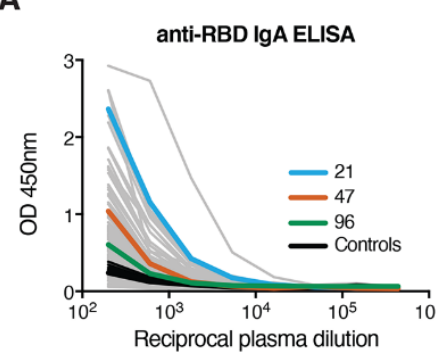

E

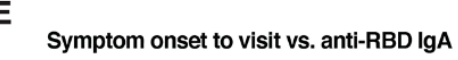

B

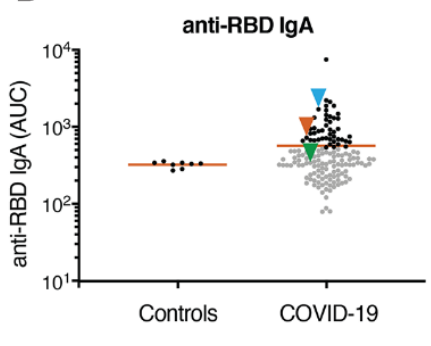

$F$

Age vs. anti-RBD IgA

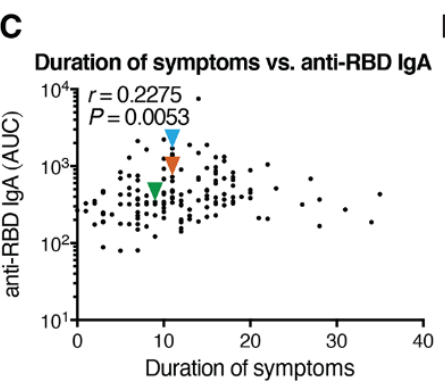

G

anti-RBD IgG vs. anti-RBD IgA

D

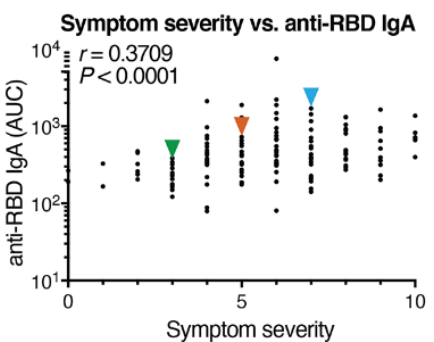

H
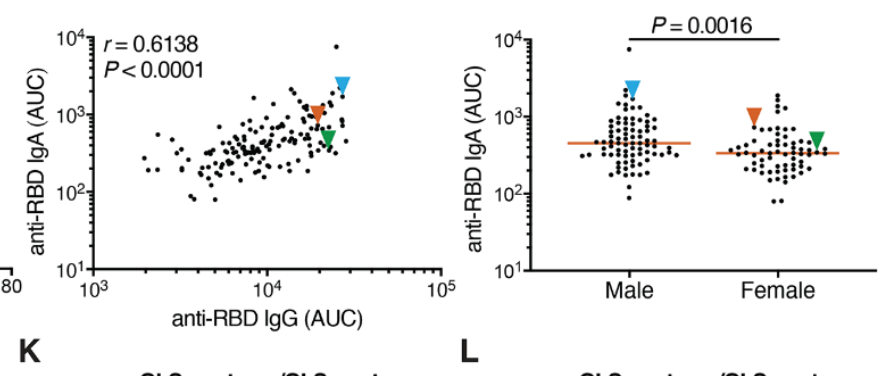

no Gl-Symptoms/GI-Symptoms

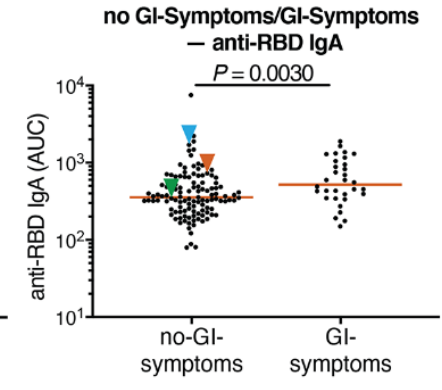

$\mathbf{L}$

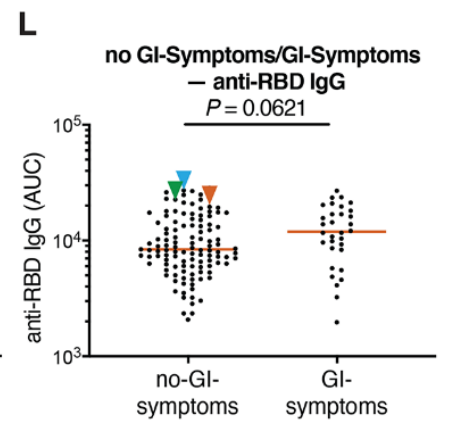

Outpatient/Hospitalized vs. anti-RBD IgA

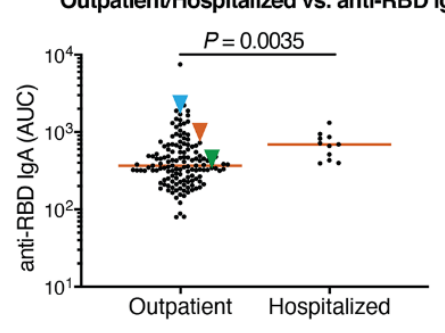

Case/Contact vs. anti-RBD IgA

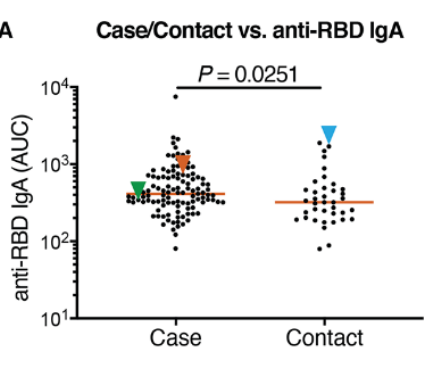

Male/Female vs. anti-RBD IgA

$P=0.0016$

\section{.}
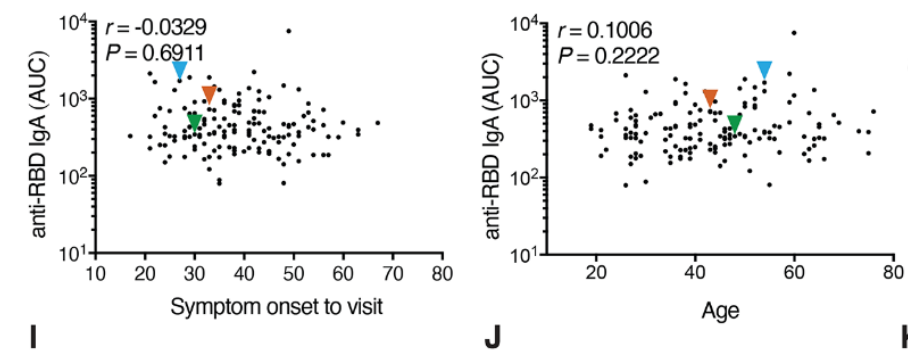

Fig. 1. Patients with COVID-19 have plasma IgA antibodies that recognize SARS-CoV-2 RBD. (A) ELISAs were used to measure plasma IgA reactivity to the SARS-CoV-2 receptor binding domain (RBD). The graph shows optical density units at $450 \mathrm{~nm}(\mathrm{OD})$ and reciprocal plasma dilutions. Negative controls in black; individuals 21, 47, 96 in blue, orange and green lines and arrowheads, respectively (11). (B) The normalized area under the curve (AUC) values for 8 controls and each of 149 individuals in the cohort were plotted. Horizontal bar indicates mean values. Black dots indicate the individuals that are 2 standard deviations over the mean of controls, gray dots represent the individuals below the same parameter. (C) The duration of symptoms in days was plotted against normalized AUC for plasma IgA binding to RBD. (D) Subjective symptom severity was plotted against the normalized AUC for IgA binding to RBD. (E) Symptom onset to time of sample collection in days was plotted against normalized AUC for plasma lgA anti-RBD. (F) Age was plotted against normalized AUC for plasma lgA antiRBD. (G) The normalized AUC of plasma anti-RBD IgG ELISA plotted against the normalized AUC for plasma IgA anti-RBD. (H) The normalized AUC of anti-RBD IgA ELISA was plotted for males $(n=83)$ and females $(n=66)$. (I) The normalized AUC of anti-RBD IgA ELISA was plotted for outpatients $(n=138)$ and hospitalized $(n=11)$ individuals. $(J)$ The normalized AUC of plasma anti-RBD IgA ELISA for all cases $(n=111)$ and contacts $(n=38)$ in the cohort was plotted. (K-L) The normalized AUC of anti-RBD IgA (K) or IgG (L) ELISA for patients with gastrointestinal $(\mathrm{Gl})$ symptoms $(\mathrm{n}=32)$ and without $\mathrm{Gl}$ symptoms $(\mathrm{n}=117)$ was plotted. The $r$ and $P$ values for the correlations in (C-G) were determined by two-tailed Spearman's. For (H-L), horizontal bars indicate median values. Statistical significance was determined using a two-tailed Mann-Whitney U test. 

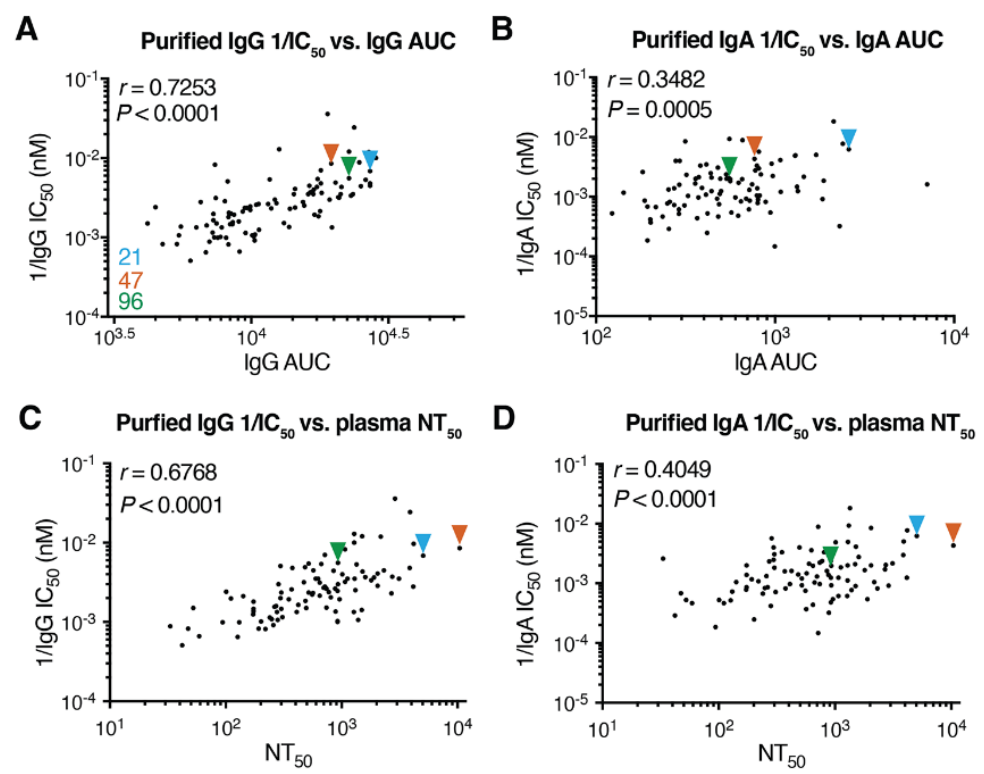

E

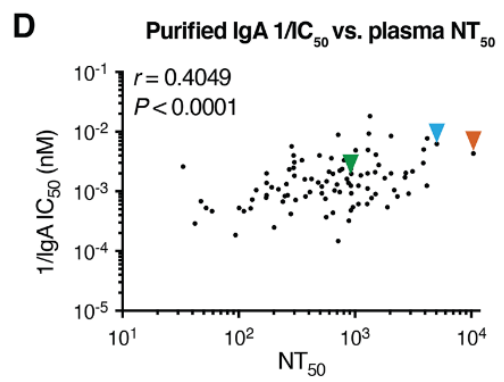

Purified $\lg G \mid \mathrm{IC}_{50}$ vs. Purified $\lg \mathrm{A} I \mathrm{C}_{50} \mathrm{~F}$

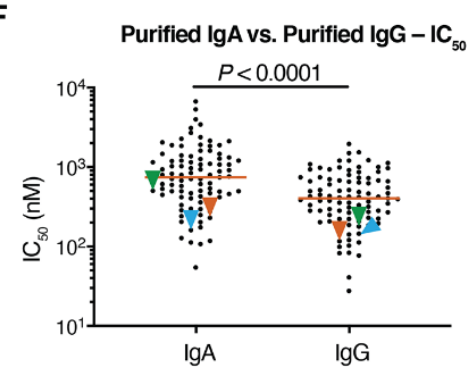

G
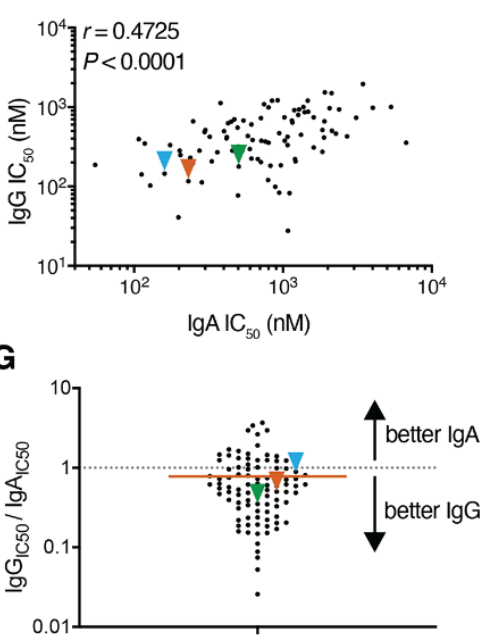

Fig. 2. SARS-CoV-2 pseudovirus is neutralized by purified IgA and IgG. Neutralization activity of plasma-purified $\lg G$ and $\lg A$ from 99 participants was measured in cell lysates of $\mathrm{HT} 1080_{\mathrm{ACE} 2} \mathrm{Cl} .14$ cells 48 hours after infection with pNL43 $\triangle$ Env-nanoluc-based SARS-CoV-2 pseudovirus. (A-B) The normalized AUC for plasma IgG (A) or IgA (B) anti-RBD ELISA was plotted against purified $\lg G(A)$ or IgA (B) pseudovirus neutralization $1 / I_{50}$ values. Individuals $21,47,96$ are indicated with blue, orange and green arrowheads, respectively. (C-D) Published plasma $\mathrm{NT}_{50}$ values (11) were plotted against purified IgG (C) or IgA (D) pseudovirus neutralization $1 / \mathrm{IC}_{50}$ values. (E) Purified IgA pseudovirus neutralization $I_{50}$ values were plotted against purified IgG pseudovirus neutralization $I_{50}$ values. (F) Purified IgA and IgG pseudovirus neutralization $\mathrm{IC}_{50}$ values were compared. (G) The plot depicts the ratio of pseudovirus neutralization $\mathrm{IC}_{50}$ values of purified $\lg G$ to $\lg A(n=95)$. The $r$ and $P$ values in $(A-E, G)$ were determined by twotailed Spearman's correlations. In $(F), P$ values were determined by two-tailed Mann-Whitney U-tests and horizontal bars indicate median values. Samples for which purified IgA $I C_{50}$ values could not be detected are not plotted, resulting in $n=95$ for panels B, D, E, F, G. 
A

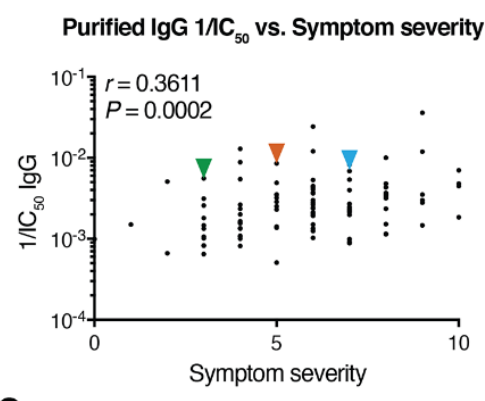

C

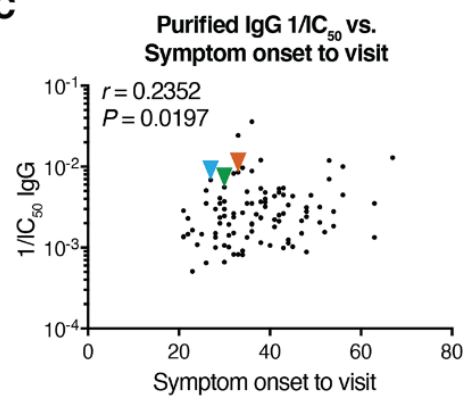

E

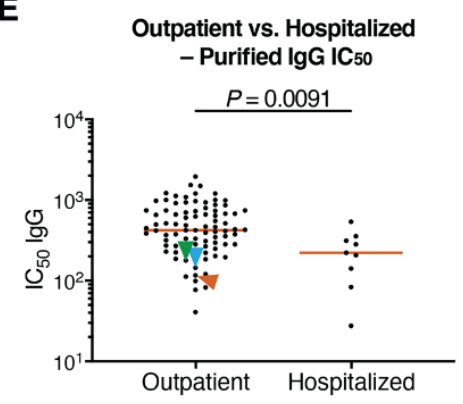

G

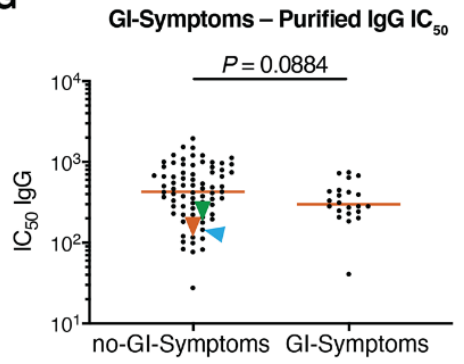

B

Purified IgA $1 / / C_{50}$ vs. Symptom severity

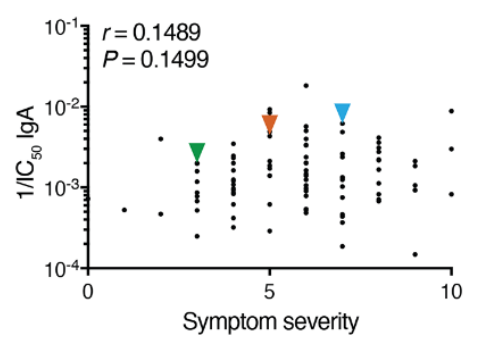

D

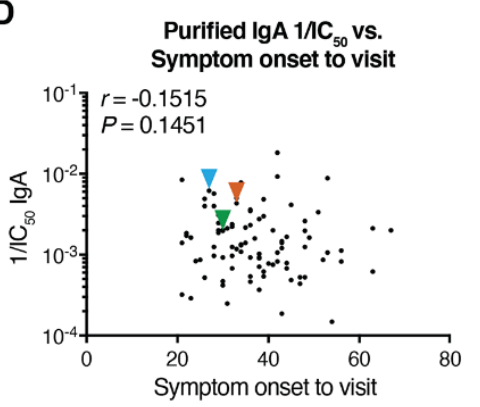

$\mathbf{F}$
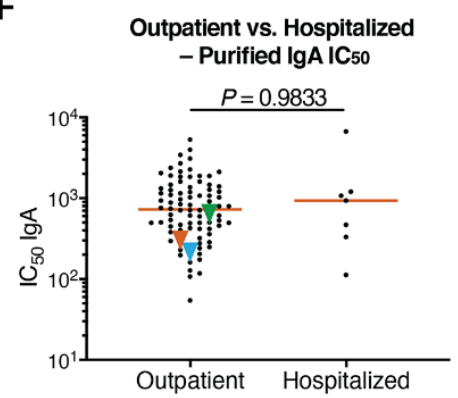

H

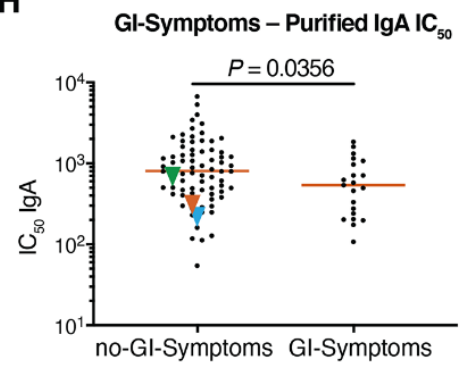

Fig. 3. Clinical parameters correlate with plasma IgA or IgG pseudovirus neutralization ability. (A, B) Symptom severity was plotted against purified $\lg G(A)$ and $\lg A(B)$ pseudovirus neutralization $1 / / C_{50}$ values. Individuals 21, 47, 96 are indicated with blue, orange and green arrowheads, respectively. (C, D) Symptom onset to time of sample collection in days was plotted against purified plasma $\lg G(C)$ and $\lg A(D)$ pseudovirus neutralization $1 / I_{50}$ values. (E, F) Purified plasma IgG (E) and $\lg A(F)$ pseudovirus neutralizing $I_{50}$ values were compared for all outpatient $(n=90)$ and hospitalized $(n=9)$ participants in the cohort. (G, $H)$ Purified $\lg G(G)$ and $\lg A(H)$ pseudovirus neutralization $\mathrm{IC}_{50}$ values for patients was compared for patients with $\mathrm{Gl}$ symptoms $(n=21)$ and without $\mathrm{Gl}$ symptoms $(\mathrm{n}=74)$. The $r$ and $P$ values in (A-D) were determined by two-tailed Spearman's correlations. In (E-H), $P$ values were determined by two-tailed Mann-Whitney U-tests and horizontal bars indicate median values. 
A

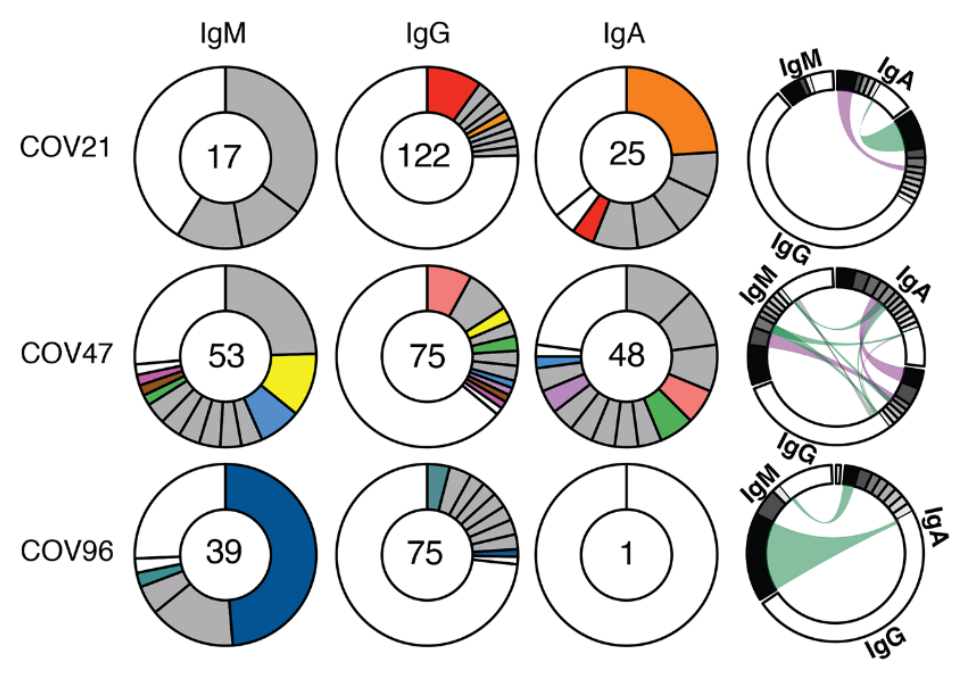

B

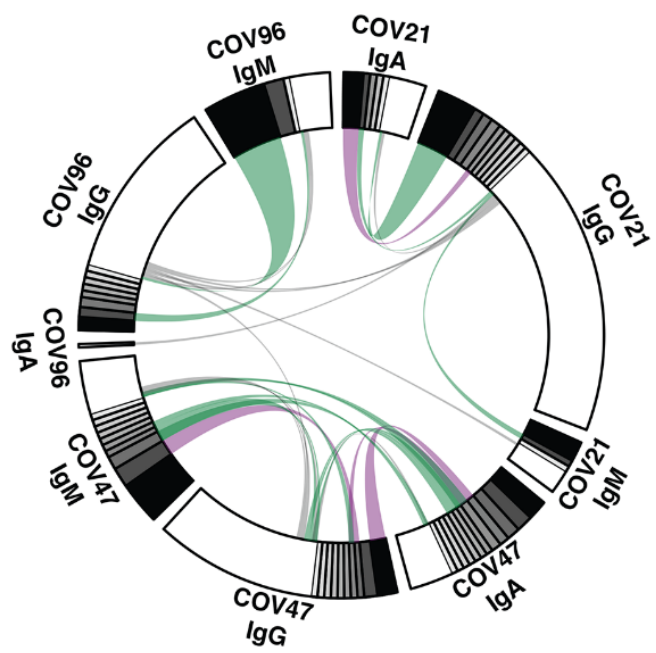

C

\begin{tabular}{|c|c|c|c|c|c|c|c|c|}
\hline & \multicolumn{4}{|c|}{ HEAVY } & \multicolumn{3}{|c|}{ LIGHT } \\
\hline & & IGHV & IGHD & IGHJ & CDRH3 & IGLV & IGLJ & CDRL3 \\
\hline \multirow{12}{*}{$\operatorname{cov} 47$} & IGM & IGHV3-21*01 & IGHD4-23*01 & IGHJ4*02 & ARERGYHGGKTSPFL & IGLV6-57*02 & IGLJ3*02 & QSYDSSNYWV \\
\hline & IGG & IGHV3-21*01 & IGHD4-23*01 & IGHJ4*02 & 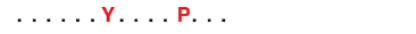 & IGLV6-57*02 & IGLJ3*02 & \\
\hline & IGG & IGHV3-21*01 & IGHD4-23*01 & IGHJ4*02 & $\ldots$. D...P. & IGLV6-57*02 & IGLJ3*02 & \\
\hline & IGA & IGHV3-21*01 & IGHD4-23*01 & IGHJ4*02 & 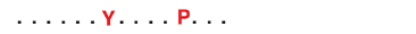 & IGLV6-57*02 & IGLJ3*02 & \\
\hline & IGA & IGHV3-21*01 & IGHD4-23*01 & IGHJ4*02 & $\ldots$. Ү... Р. & IGLV6-57*02 & IGLJ3*02 & \\
\hline & IGA & IGHV3-21*01 & IGHD4-23*01 & IGHJ4*02 & $\ldots \ldots \gamma_{\ldots}$ & IGLV6-57*02 & IGLJ3*02 & \\
\hline & IGM & IGHV4-59*01 & IGHD3-10*01 & IGHJ4*02 & ARYQLAPGSGSYYNWGGYPRESEYYFDY & IGLV2-11*01 & IGLJ3*02 & CSYAGSYTWV \\
\hline & IGM & IGHV4-59*01 & IGHD3-10*01 & IGHJ4*02 & & IGLV2-11*01 & IGLJ3*02 & \\
\hline & IGM & IGHV4-59*01 & IGHD3-10*01 & IGHJ4*02 & & IGLV2-11*01 & IGLJ3*02 & \\
\hline & IGM & IGHV4-59*01 & IGHD3-10*01 & IGHJ4*02 & & IGLV2-11*01 & IGLJ3*02 & \\
\hline & IGG & IGHV4-59*01 & IGHD3-10*01 & IGHJ4*02 & & IGLV2-11*01 & IGLJ3*02 & \\
\hline & IGA & IGHV4-59*01 & IGHD3-10*01 & IGHJ4*02 & 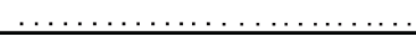 & IGLV2-11*01 & IGLJ3*02 & \\
\hline
\end{tabular}

Fig. 4. Characterization of monoclonal anti-SARS-CoV-2 RBD IgM, IgG and IgA antibodies. (A) B cells producing of IgM, IgG and IgA from three individuals, COV21, COV47, and COV96, were analyzed and clonality was evaluated. The number in the inner circle indicates the number of sequences analyzed for the individual denoted. Pie slices size is proportional to the number of clonally related sequences. Colored pie slices indicate clones or singlets that share the same IGHV and IGLV genes and have highly similar CDR3s across isotypes. Grey indicates clones that are not shared. White indicates singlets that are not shared. The right side circos plots show the relationship between antibodies of different isotypes that share same IGH V(D)J and IGL VJ genes and have highly similar CDR3s. Purple, green and grey lines connect related clones, clones and singles, and singles to each other, respectively. (B) Circos plot shows sequences from all three individuals with clonal relationships depicted as in (A). (C) Sample sequence alignment for antibodies of different isotypes isolated from individual COV47 that display same IGH $\mathrm{V}(\mathrm{D}) \mathrm{J}$ and IGL VJ genes and highly similar CDR3s. Amino acid differences in CDR3s to the reference sequence (bold) are indicated in red, and dots represent identical amino acids. 
A

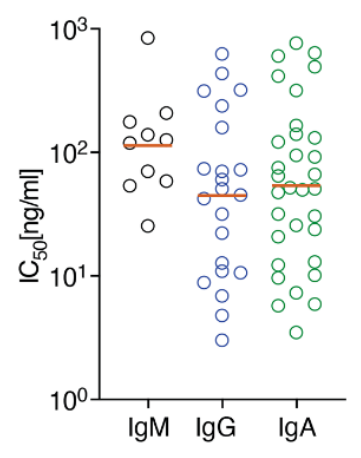

C
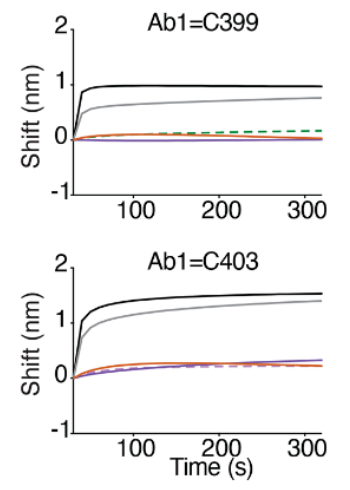

B

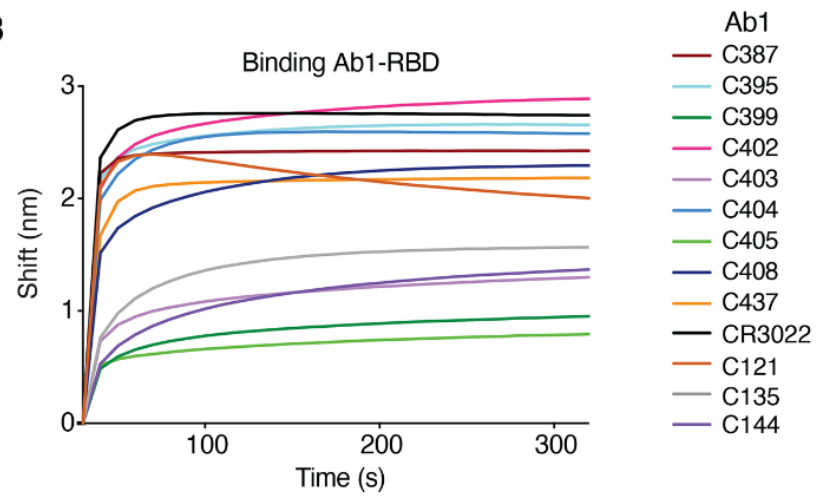

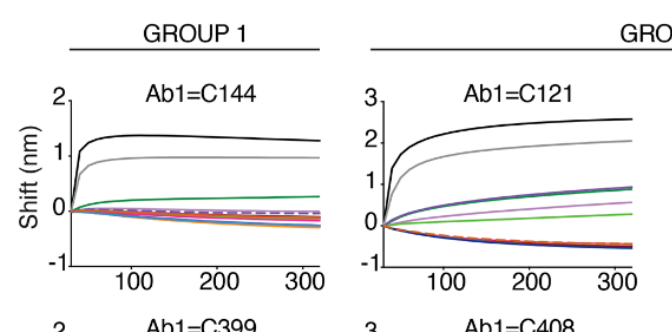
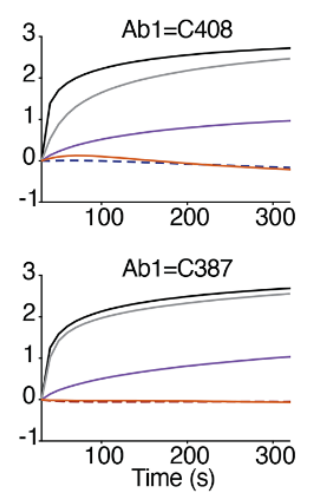

GROUP 2
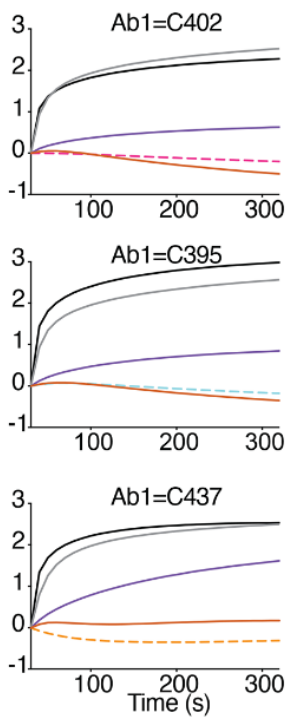
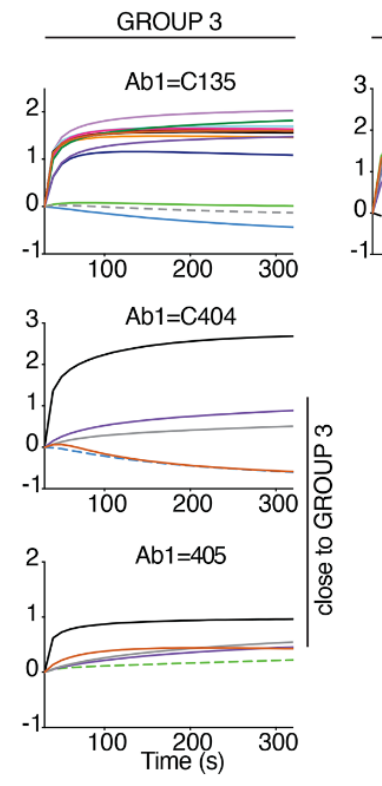

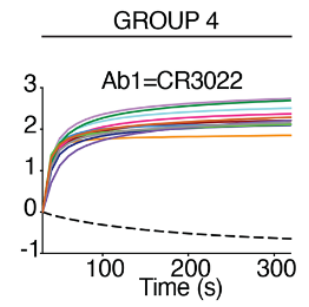

- $\mathrm{C} 387$

- C395

- C399

- $\mathrm{C} 402$

- $\mathrm{C} 403$

- $\mathrm{C} 404$

- C405

- $\mathrm{C} 408$

- C437

- CR3022

- C121

- C135

Fig. 5. Monoclonal IgA and IgM antibodies bind and neutralize SARS-CoV-2 in vitro. (A) Pseudovirus $\mathrm{IC}_{50}$ neutralization values for $\lg A$ and $\lg \mathrm{M}$ monoclonal antibodies and IgG monoclonal antibodies from the same individuals (11). Antibodies with an $\mathrm{IC}_{50}$ less than $1000 \mathrm{ng} / \mathrm{ml}$ are shown. Orange lines indicate geometric mean. (B) RBD binding was quantified by biolayer interferometry. (C) The binding of a second antibody (Ab2) to preformed first antibody (Ab1)-RBD complexes was also quantified by biolayer interferometry. Dotted line denotes where Ab1 and Ab2 are the same, and Ab2 is color coded as indicated. We tested selected IgA antibodies against preformed complexes representing antibodies that bind to different structurally determined epitopes (59) from class 1,2 , 3 or 4 (C144-, C121-, C135- or CR3022-RBD respectively). 
A
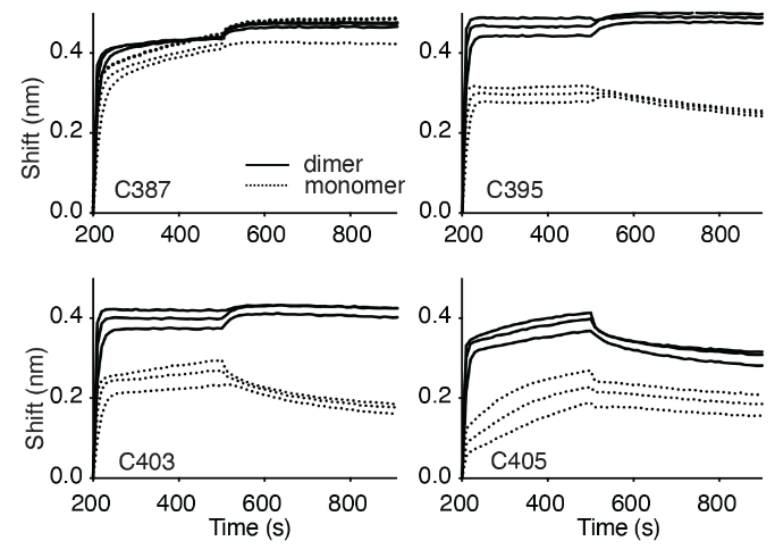

C

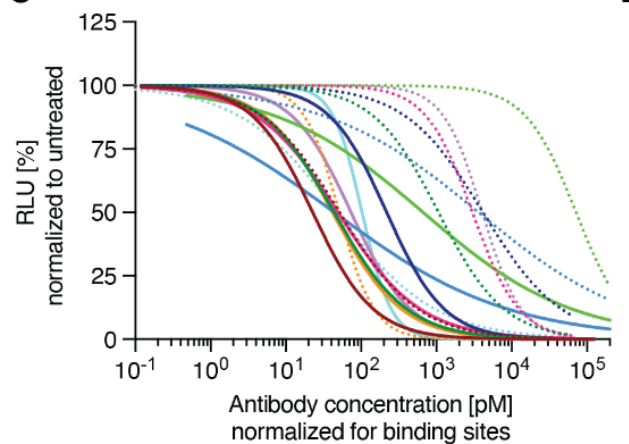

D

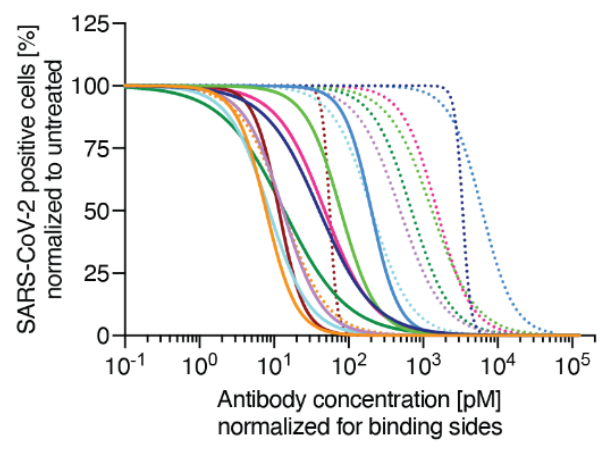

B

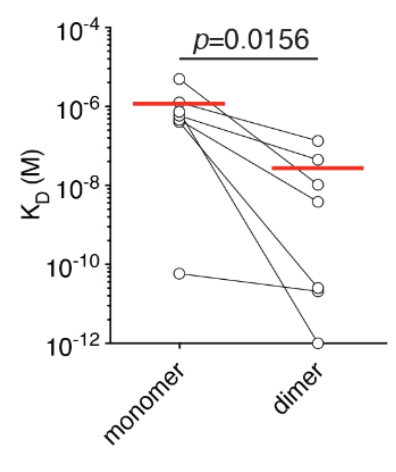

E

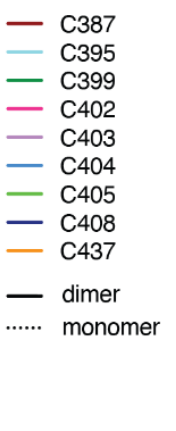

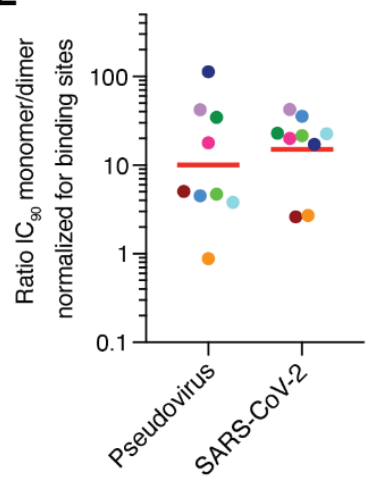

Fig. 6. IgA dimers bind to RBD and neutralize authentic SARS-CoV-2 more potently than monomers in vitro. (A) Graphs depict binding affinity measurements of individual IgA monomers and corresponding dimers. (B) The dissociation constant $\left(K_{D}\right)$ values of monomers and dimers was compared. Horizontal lines indicate mean $(n=7)$. (C-D) The normalized relative luminescence values for cell lysates of $293 T_{A C E 2}$ cells after infection with SARS-CoV-2 pseudovirus (C) or normalized percentage of SARS-CoV-2 positive Vero E6 cells 48 hours after infection with SARS-CoV-2 authentic virus (D). Values obtained in the absence of antibody are plotted at $x=0.1$ to be visible on log-scale) in the presence of increasing concentrations of indicated monoclonal antibodies in their monomeric or dimeric form. Shown are four-parameter nonlinear regression curve fits of normalized data. (E) IC 90 values were compared between monomer to dimers after normalization to number of antibody binding sites. For (B) Student's $t$ test was used. 